\title{
Current Systems in the Earth's Magnetosphere
}

\author{
N. Yu. Ganushkina ${ }^{1,2}$, M. W. Liemohn ${ }^{1}$, S. Dubyagin ${ }^{2}$ \\ ${ }^{1}$ University of Michigan, Ann Arbor, Michigan, USA. \\ ${ }^{2}$ Finnish Meteorological Institute, Earth Observations, Helsinki, Finland.
}

\section{Key Points:}

- The basic structure and dynamics of the primary electric current systems in the Earth's magnetosphere is presented and reviewed.

- The implications of understanding magnetospheric current systems is discussed, including paths forward for new investigations.

- The concept of an electric current is reviewed and compared with other approaches to investigating the physics of the magnetosphere.

This is the author manuscript accepted for publication and has undergone full peer review but has not been through the copyediting, typesetting, pagination and proofreading process, which may lead to differences between this version and the Version of Record. Please cite this article as doi: 10.1002/2017RG000590

Corresponding author: N. Yu. Ganushkina, ganuna@umich.edu

This article is protected by copyright. All rights reserved. 


\section{Abstract}

The basic structure and dynamics of the primary electric current systems in the Earth's magnetosphere is presented and discussed. In geophysics, the word current is used to describe the flow of mass from one location to another, and its analogue of electric current is a flow of charge from one place to another. An electric current is associated with a magnetic field, and they combine with the Earth's internally-generated dipolar magnetic field to form the topology of the magnetosphere. The concept of an electric current is reviewed and compared with other approaches to investigating the physics of the magnetosphere. The implications of understanding magnetospheric current systems is discussed, including paths forward for new investigations with the robust set of observations being produced by the numerous scientific and commercial satellites orbiting Earth.

\section{Introduction}

The common definition of a current is a flow of fluid. This is a ubiquitous occurrence in the geosciences. One example is molten rock motion inside the Earth, which can take many millenia to complete their loop and return to their original location [e.g., Jellinek and Manga, 2004; Korenaga, 2008]. Another example is ocean currents, which are flows that take centuries to circulate around the globe, often making several depth changes as temperature and salinity are altered along the path [e.g., Gordon, 1986; Dijkstra and Ghil, 2005]. A third example is groundwater flow through cracks in the rock, which takes a very complicated route through surface water reservoirs and perhaps the atmosphere before a loop through the hydrological cycle is completed [e.g., Bierkens, 2015; Fan, 2015]. A fourth and final example is air currents such as the Jet Stream or the Trade Winds, which are really segments of the large-scale atmospheric circulation system [e.g., Emanuel et al., 1994; Egger et al., 2007; Payne and Magnusdottir, 2016].

Currents can be related to the forces acting on the fluid and, therefore, currents can be a critical diagnostic in examining the physical processes at work in the natural world. Moreover, the resulting change in the state of the system often influences those original forces. This implies that current system analysis is a nonlinear problem in which both negative and, sometimes, positive feedback mechanisms complicate the answer.

The currents mentioned above, however, are all electrically neutral fluids, for which the word current refers to a net shift of mass from one location to another within the sys- 
tem. Electric currents are somewhat different and more narrowly defined. Specifically, an electric current refers to a net flow in charge from one location to another within the system. The mass flow, especially for electric currents dominated by electron motion, could be insignificant, but the influence on the system could still be dramatic. While both neutral and electric currents are related to forces acting on the fluid, the specific forces involved can be rather different, and, therefore, electric currents deserve their own special consideration.

Nearly everyone in the world comes into regular contact with electric currents. The most common form is the electric power distribution grid; any time an electrical plug is inserted into a live socket, electric currents flow through the wires. When the plug is very close but not fully within the socket, occasionally a spark can be seen jumping across the small air gap between them. A force is there and the electric current wants to flow, once the resistance is small enough to allow it. Power lines, however, come in pairs, and the current into the plug along one prong is matched by an equal current out of the plug along the other prong. Eventually, the electric current completes a circuit back to the voltage source. Similarly, a lightning stroke is a rapid transfer of charge from the cloud to the ground (or vice versa), carving a channel through the air with such suddenness that the air lights up in a flash and a pressure wave causes a thunderous noise. This transfer of charge is just part of a larger current system, the global atmospheric electric circuit, closed by the small but persistent fair-weather current in the other direction [e.g., Bering, 1995; Rycroft and Harrison, 2012].

While power grid electric currents are confined to a narrow channel, i.e., the wire, electric currents in outer space are under no such confinement restrictions and often expand into vast volumes. The main limiter on their size is the location and intensity of the related forces acting on the charged particles. For example, in astrophysics, rotating pulsars generate intense radially directed currents associated with a disk-like magnetic topology around them [e.g., Kuijpers et al., 2015]. Within our solar system, the scenario is reversed. The Sun emits a supersonic, electrically charged, magnetized gas called the solar wind and near the ecliptic plane (although sometimes skewed far from it), there exists an azimuthal current loop flowing clockwise for one solar cycle and then counterclockwise the next [e.g., Winterhalter et al., 1994; Smith, 2001]. 
Near-Earth space is also a place to find electric currents. Ever since the invention of magnetometers sensitive enough to detect perturbations to the Earth's field on the order of a percent or better, currents that are related to the magnetic fields through Ampere's law have been known to exist in the near-Earth space [e.g., Gillmor, 1997]. The Earth has a strong internally-generated dipolar magnetic field that extends into outer space around the planet. Because of the existence of the solar wind and the interplanetary magnetic field (IMF) associated with it, this dipolar configuration is compressed on the dayside and elongated on the nightside. Several current loop systems were identified early on in the space age as the basic topology of the magnetosphere was discovered [e.g., Heikkila, 1984]. Eventually numerical models were able to reproduce this basic structure and current systems could be readily identified and isolated [e.g., Siscoe et al., 2000]. Lately, new multi-spacecraft missions such as Cluster, THEMIS (Time History of Events in the Magnetosphere-Ionosphere System), Swarm, and MMS (Magnetospheric MultiScale) have allowed for a deeper and more sophisticated approach to understanding the structure and dynamics of current systems around Earth.

While there have been several recent topical reviews of magnetospheric electric currents [e.g., Ebihara and Ejiri, 2003; Phan et al., 2005; Daglis, 2006; Lotko, 2007; Keiling, 2009; Walsh et al., 2014; Ganushkina et al., 2015; McPherron, 2015; Kepko et al., 2015; Lhr et al., 2017] and even some Commentaries outlining the next steps in current system research [e.g., Lockwood, 2016; Liemohn et al., 2016; Dunlop et al., 2016], these are either focused on a subset of magnetospheric currents or have been pitched at a high level and are only for knowledgeable researchers in those particular fields. It is useful, therefore, to compile a more general review that appeals to a broader and less specialized audience. This review addresses this need for an introductory primer on magnetospheric current systems. In fact, it will build directly from Ganushkina et al. [2015] for a more detailed description of current understanding and recent advancements. The present paper focuses on schematics of the large-scale, global nature of current systems in the magnetosphere, their general structure in the typical magnetosphere, and basic properties of their dynamics during active times.

\section{What Is a Current? B-v vs. E-J Paradigm}

Electric current is defined as a flow of charge transported by particles. The density of electric current $\boldsymbol{J}$ (the charge per second that flows across a unit area perpendicular to 
the flow direction) at any point in space $\boldsymbol{r}$ and in time $t$ is given in general form as

$$
\boldsymbol{J}(\boldsymbol{r}, t)=\sum_{i} q_{i} \int \boldsymbol{v} f_{i}(\boldsymbol{r}, \boldsymbol{v}, t) d^{3} \boldsymbol{v}
$$

where $q_{i}$ is the particle charge for the i-species, $v$ is the particle velocity and $f_{i}$ is the distribution function. The sum is taken over all the species in the plasma.

The current density is present in one of Maxwell's equations (Ampere's law), which relates the magnetic field $\boldsymbol{B}$ with the current density $\boldsymbol{J}$ :

$$
\nabla \times \boldsymbol{B}=\mu_{0}\left(\boldsymbol{J}+\epsilon_{0} \frac{\partial \boldsymbol{E}}{\partial t}\right)
$$

where $\mu_{0}$ is the permeability of free space, $\epsilon_{0}$ is the permittivity of free space and $\boldsymbol{E}$ is the electric field.

As follows from Equation 1, a current exists nearly everywhere where plasma is present. In the Earth's magnetosphere, the paths of the currents are not fixed and there is a non-zero current essentially everywhere throughout the whole volume. For static conditions, if the plasma pressure is anisotropic, the current density perpendicular to the magnetic field $\boldsymbol{J}_{\perp}$ can be written following Parker [1957]:

$$
\boldsymbol{J}_{\perp}=\frac{\boldsymbol{B}}{B^{2}} \times\left[\nabla p_{\perp}+\left(p_{\|}-p_{\perp}\right) \frac{(\boldsymbol{B} \cdot \nabla) \boldsymbol{B}}{B^{2}}\right]
$$

where $p_{\|}$and $p_{\perp}$ are plasma pressure, parallel and perpendicular to the magnetic field, respectively. This equation is valid if a quasi-static equilibrium exists (force-balanced state) and inertial terms can be neglected. Equation 3 can be simplified for isotropic pressure $p$ as

$$
\boldsymbol{J}_{\perp}=\frac{\boldsymbol{B} \times \nabla p}{B^{2}} .
$$

Figure 1 demonstrates schematically the consequences following the Equation 4 as the appearance of a current when plasma pressure gradient is present. Figure 1a shows some radial distribution of plasma pressure in the near-Earth magnetosphere in Gaussian form selected for simplicity (Earth is at the center of coordinates). Due to the shape of the pressure distribution, the pressure gradients will be of the same magnitude but with different directions (Figure 1b). If the magnetic field in the magnetopshere is considered to be dipolar in the zeroth order approximation, then the magnetic field intensity decreases as $\sim 1 / r^{3}$ with radial distance $r$ as in Figure 1c. The azimuthal electric current will flow eastward at distances earthward from the pressure peak and westward at distances tailward 
from the pressure peak. As it can be seen, even if the pressure gradients are similar, the westward current is larger that the eastward current due to the decrease of the magnetic field. In spite of the apparently complex physics, nearly all current systems discussed below can be understood using simple MHD static force balance (Equation 4). This equation emphasizes the importance of plasma pressure gradients for electric currents and predicts that intense currents must exist at sharp boundaries between different plasma populations.

In the formulation of magnetohydrodynamics (MHD), however, electric field and current density become a secondary set of variables to the dominant pair of magnetic field and bulk velocity. Maxwell's equations relate these values and the standard MHD equation set includes $\boldsymbol{B}$ and $\boldsymbol{v}$ rather than $\boldsymbol{E}$ and $\boldsymbol{J}$ among the state variables. Many researchers, however, discuss the physics of the magnetosphere in terms of $\boldsymbol{E}$ and $\boldsymbol{J}$ rather than $\boldsymbol{B}$ and v. Lui [2000] discussed the benefits of addressing magnetospheric dynamics through the $\boldsymbol{E}$ - $\boldsymbol{J}$ paradigm, determining that there are several key physical processes that are particularly well suited for study in this approach, such as particle acceleration, plasma waves, and breaking of the frozen-in magnetic field condition. These differing views prompted Parker's writing of his "alternative paradigm" paper [Parker, 1996], detailing the assumptions implicit in the $\boldsymbol{E}-\boldsymbol{J}$ paradigm and arguing in favor of the $\boldsymbol{B}-\boldsymbol{v}$ paradigm. This argument has been restated several times since then [e.g., Parker, 2000; Vasyliunas, 2001, 2005]. For example, Vasyliunas [2001] demonstrated that the MHD formulation, under the right assumptions and initial conditions, yields a result in which bulk flow produces electric fields but not vice versa. One of the assumptions of the $\boldsymbol{E}-\boldsymbol{J}$ paradigm is that of stationarity, that in order to discuss a current system, the 3D electric current configuration forms instantaneously to match the associated magnetic field topology. This isn't really a problem, though. The magnetic fields and currents are directly related without a time delay, so the instantaneous magnetic field topology must be consistent with the instantaneous current configuration. The assumption being applied here is that the current should close in a simple formed loop. Physics dictates that closure must happen, but the loop might be very complicated and pass through many of the simplistically defined current systems before returning to its location of origin. That currents close in simple, well-defined loops is not actually a requirement of the $\boldsymbol{E}-\boldsymbol{J}$ paradigm; the currents can have any level of complexity to their eventual closure. Unfortunately, this assumption is often associated with the $\boldsymbol{E}-\boldsymbol{J}$ paradigm and is perceived as a weakness of this approach. Interestingly, magnetic fields are also physically dictated to close in loops, and magnetic field lines can be just as 

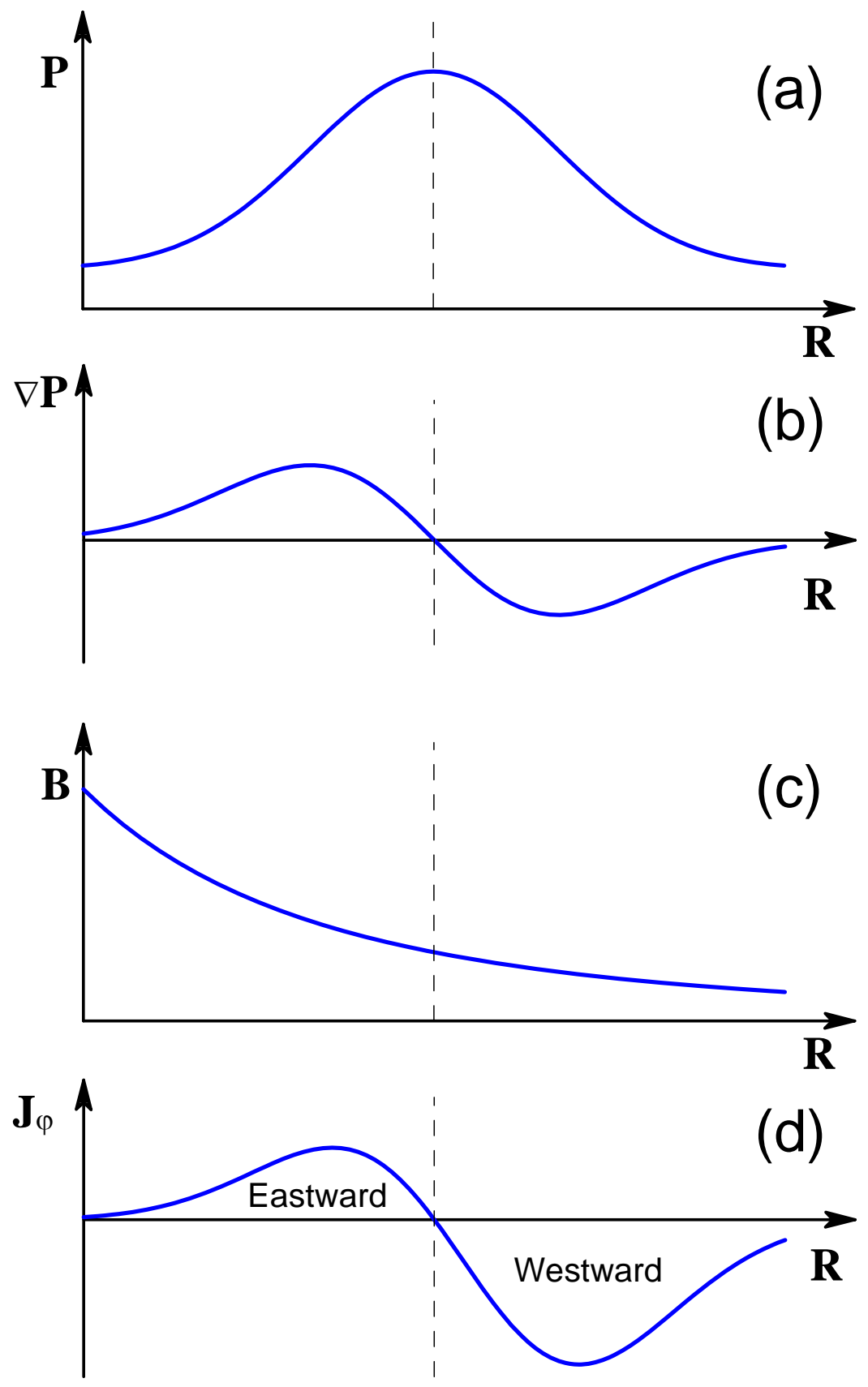

Figure 1. Schematic representation for the appearance of a current when a plasma pressure gradient is present in the Earth's magnetosphere: (a) Plasma pressure distribution with a peak, (b) Presence of the plasma pressure gradients, (c) Magnetic field decrease with radial distance, (d) azimuthal currents in eastward and westward directions. 
complicated as current loops. Indeed, the concept of an open magnetic field line implies that it does not close on itself within the system being considered. In summary, both approaches are far more complex than the basic diagrams drawn to represent the magnetic field topology or the current system configuration in space.

So, why study electric currents and draw simple diagrams of current systems? The short answer is because it is useful for many researchers to do so. Developing an understanding of electric current systems flowing in near-Earth space has offered insight into the structure, dynamics, and dominant physical processes throughout the epoch of magnetospheric physics discovery. Since the beginning of the field, researchers have been discussing the flow of electric currents in near-Earth space. The histories by Stern [1989] and Gillmor [1997] document this usage of current system analysis, including scientists as early as Gauss [Gauss, 1839] in the early-to-mid 1800s considering the possibility of electric currents in space altering the magnetic field observed on the ground. Carrington [1860] connected auroral displays with magnetometer perturbations during the superstorm that now bears his name, and Stewart [1882] made the connection that solar illumination ionizes the upper atmosphere to allow for electric currents to flow in this region. In his famous terrella laboratory studies of Sun-Earth connections, Birkeland [1908, 1913] postulated that field-aligned currents existed to connect the solar wind to the Earth's ionosphere, leading to the aurora. Since then, an understanding of a suite of current systems flowing in near-Earth space has arisen, associated with the topology of the magnetosphere, as detailed in numerous reviews of the topic [e.g., Stern, 1976, 1977, 1996; Fairfield, 1977; Potemra, 1979; Heikkila, 1984; Akasofu, 1984; Mauk and Zanetti, 1987].

This review is not written to convince the reader of the correctness or rightness of one paradigm over the other. The argument for the $\boldsymbol{B}-\boldsymbol{v}$ paradigm has been made [e.g., Vasyliunas, 2001] and many find that to be a useful framework for addressing magnetospheric physics. This review is written to consolidate our understanding of magnetospheric current systems in a way that is easily accessible for those just starting in the field of space physics, or even for those outside of the field. It presents the basic structure of the main current systems in the magnetosphere, the typical dynamics of these current systems during active periods, and the physical processes governing these configurations and temporal changes. 


\section{Main Current Systems}

The distortion of the terrestrial internal magnetic field due to the interaction with the solar wind and formation of the magnetosphere is accompanied by electric currents which flow in the magnetosphere. These currents are important constituents of the dynamics of plasma around the Earth. They transport charge, mass, momentum and energy and they themselves generate magnetic fields which distort significantly pre-existing fields.

When solar wind comes close to the Earth, it can not easily penetrate the Earth's internally generated magnetospheric magnetic field. The magnetopause, a surface boundary separating the two different regions, is formed. The kinetic pressure of the solar wind compresses the terrestrial magnetic field on the dayside and this is associated with magnetopause current flowing across the magnetopause. On the nightside, magnetic field is stretched and a long magnetotail is formed. The magnetotail current exists there, one part of it flowing in the center of the tail across the magnetosphere from dawn to dusk and the other making two loops, above and below the magnetotail center, closing the central current through the magnetopause.

The magnetospheric plasma consists mainly of ions and electrons which come from the solar wind and the terrestrial ionosphere. In the Earth's magnetospheric magnetic field, particles with $\mathrm{keV}$ (kiloelectron volt) energies gyrate around and bounce along magnetic field lines and move (drift) around the Earth in a matter of hours. Westward drift of ions and eastward drift of electrons, along with their gyration motion in a region with a pressure gradient, results in a net charge transport and corresponding ring current flowing around the Earth.

There exist also currents flowing along magnetic field lines, field-aligned currents, mainly carried by electrons, which connect the magnetospheric currents with ionospheric currents. Several current systems are present in the conducting Earth's ionosphere but their detailed description is beyond the scope of the present review.

As the Earth's magnetosphere responds to changes in solar activity, the main magnetospheric current systems can undergo dramatic changes with new transient current systems being generated. The key currents of the magnetosphere are presented in the sections below. 


\subsection{Chapman-Ferraro Magnetopause Currents}

The idea that the Earth's own magnetic field diverts the solar wind that leads to forming a cavity, that is referred as magnetosphere, where the solar wind does not have direct access was suggested well before the spaceflight era by Chapman and Ferraro [1931] and confirmed by Explorer 10 and 12 measurements [e.g., Cahill and Amazeen, 1963]. The typical values of undisturbed solar wind speed in the vicinity of the Earth is about $400 \mathrm{~km}$ per second. This speed of the solar wind is supersonic since it exceeds the velocities of fast plasma waves whcih are about $50-100 \mathrm{~km}$ per second. The magnetosphere is an obstacle immersed in the supersonic solar wind flow and, therefore, the bow shock is formed in front of it, similarly as the shock is formed when an aircraft is moving in the atmosphere with the speed that exceeds the velocity of sound waves. This shock front slows down, compresses, and heats the solar wind plasma. The region between the magnetosphere and the shock front is called the magnetosheath. As a result of the deceleration at the shock, the flow in the magnetosheath is not supersonic. The speed of the solar wind increases when it moves around the magnetosphere, from the subsolar point to the flanks of the magnetosphere.

For the magnetosheath plasma, the particle pressure is of key importance, whereas inside the magnetosphere, plasma is more tenuous and the magnetic pressure plays a major role. The magnetopause separates those two regions and an extensive current, called the Chapman-Ferraro current, flows across it. Figure 2 presents a schematic picture of the Chapman-Ferraro dayside magnetopause currents. In equilibrium, the magnetic pressure inside the magnetopause $p_{B}=\frac{B^{2}}{2 \mu_{0}}$, where $\mu_{0}=4 \pi \cdot 10^{-7} \mathrm{H} / \mathrm{m}$ is the permeability of free space, is equal to the sum of thermal and magnetic pressures in the magnetosheath, which is, in turn, equal to the dynamic pressure of the solar wind $p=\rho_{s w} u_{s w}^{2}$, where $\rho_{s w}$ is the mass density of the solar wind and $u_{s w}^{2}$ is the solar wind flow speed upstream of the bow shock. This balance defines the location of the magnetopause. If we assume the dipole magnetic field for simplicity, its strength as a function of radial distance $r$ is $B(r)=B_{E}\left(\frac{R_{E}}{r}\right)^{3}$, where $B_{E}=3 \cdot 10^{-5} T$ is the magnetic field at the equator on the Earth's surface and $R_{E}$ is the Earth's radius of $6371 \mathrm{~km}$. The magnetopause force balance gives the distance $r_{m p}$ to the nose of the magnetopause, or subsolar point, $\frac{r_{m p}}{R_{E}}=\left(\frac{B_{E}^{2}}{2 \mu_{0} \rho_{s w} u_{s w}^{2}}\right)^{1 / 6}$. In reality, the magnetic field is compressed on the dayside and the magnetopause is a current layer which produces the distortion of the dipole magnetic field. The magnetic field just inside the magnetopause is about two times larger than that of a dipole. The modified 
equation for the magnetopause distance is $\frac{r_{m p}}{R_{E}}=2^{1 / 3}\left(\frac{B_{E}^{2}}{2 \mu_{0} \rho_{s w} u_{s w}^{2}}\right)^{1 / 6}$. On average, the nose of the magnetopause is located at about $10 R_{E}$ on the dayside. The magnetopause distance is inversely proportional to the solar wind dynamic pressure to the $1 / 6^{\text {th }}$ power. If the activity of the Sun increases and the dynamic pressure of the solar wind becomes higher, the magnetopause current intensifies and the magnetopause moves closer to the Earth. When the solar wind pressure is ten times larger than the typical values, the magnetopause can come as close as $6.5 R_{E}$. Away from the nose, the current magnitude decreases as the magnetopause moves farther from the Earth where the magnetic field is weaker [e.g., Coroniti and Kennel, 1972; Petrinec and Russell, 1996]. At the high latitudes, there exist co-called cusps (in both the northern and southern hemispheres) of the magnetosphere [e.g., Hedgecock and Thomas, 1975], they mark the separation between the magnetic field lines going sunward and tailward. The magnetic field reaches its minima near the cusp regions, and the solar wind plasma can penetrate up to the top of the atmosphere there. The magnetopause current flows around the cusps as shown in Figure 2.

The generation of the magnetopause current can be understood if we consider the trajectories of magnetosheath protons and electrons and their interaction with the geomagnetic field. The best illustration can be found in Kivelson and Russell [1995], Figure 9.2. When they move to the regions with larger magnetic field, they are forced to return to the magnetosheath after only a half of gyration. Protons and electrons gyrate in opposite directions around the magnetospheric field, therefore, their motion within the boundary results in a current. As the magnetic field within the boundary is oriented predominantly northward, the current will flow from dawn to dusk (see Figure 2) across the equatorial magnetopause and from dusk to dawn across the high-latitude magnetopause tailwards of the cusp openings. Although this simple scenario predicts the magnetopause current sheet thickness to be of order of one ion gyroradius, the observations from the International Sun-Earth Explorer (ISEE) spacecraft [e.g., Le and Russell, 1994] and Cluster satellites [e.g., Haaland et al., 2004] showed that it is of 5-10 ion gyroradii (several hundred km). This larger thickness is due to the effect of kinetic instabilities smearing out the thin current sheet. The magnetopause currents form closed loops across the dayside part of the magnetosphere (see Figure 2), with an average current density of $20 \mathrm{nA} / \mathrm{m}^{2}$. The magnetopause surface current density can be related to the plasma pressure jump across magnetopause using Equation 4. For $2 \mathrm{nPa}$ of pressure on the magnetosheath side of magnetopause (we assume that there is no plasma inside the magnetopause), which is close to 


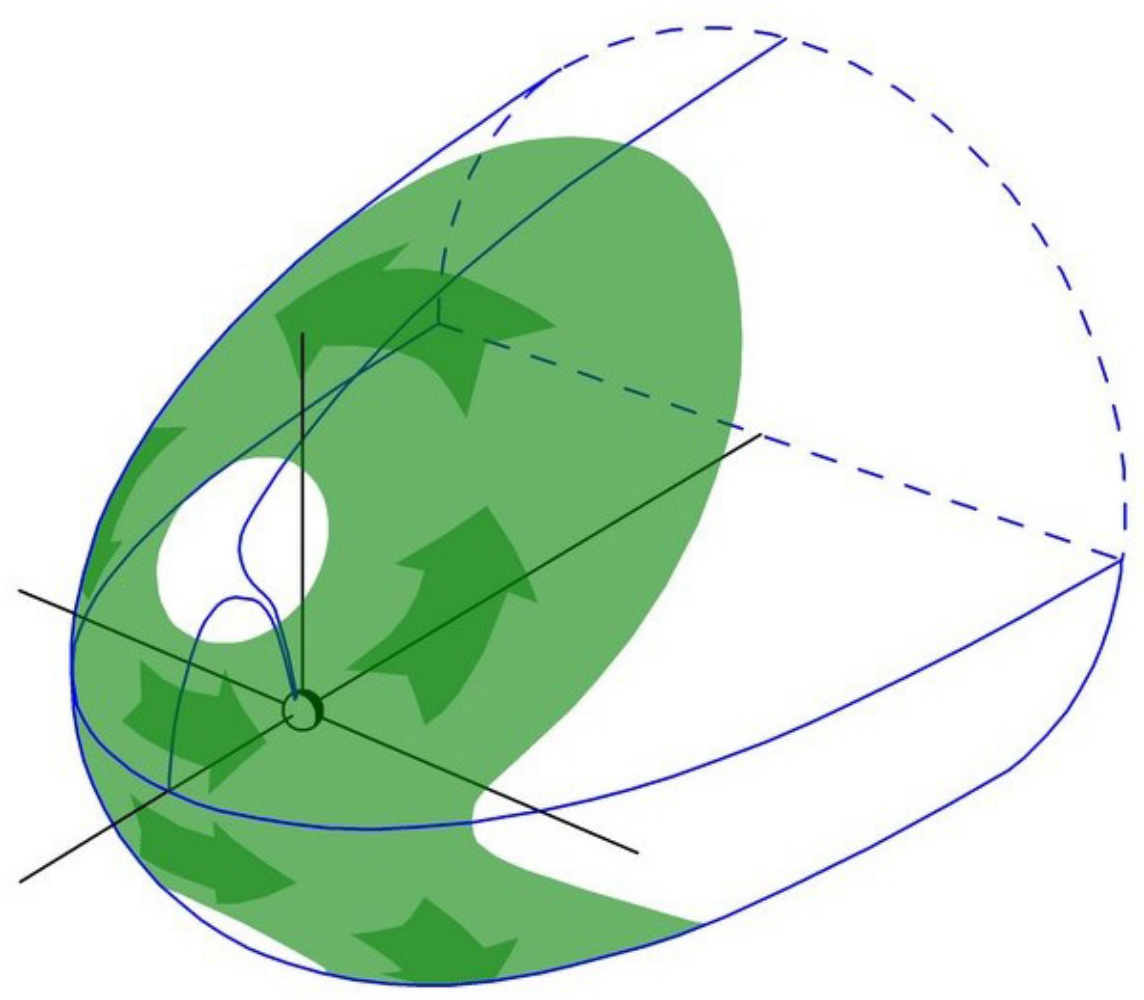

Figure 2. The Chapman-Ferraro dayside magnetopause currents are shown as a green-shaded surface on a simple wire diagram of the magnetopause. The Earth is the small sphere at the axis origin and the Sun is to the lower left. 
the solar wind dynamic pressure, and for $60 \mathrm{nT}$ of the magnetic field inside the magnetopause layer, the surface current density is $0.03 \mathrm{~A} / \mathrm{m}$.

\subsection{Tail Current with Closure via Return Current on the Magnetopause}

Magnetic field observations made by the Interplanetary Monitoring Platform (IMP) 1 satellite [Ness, 1965; Speiser and Ness, 1967] revealed that the Earth's magnetosphere forms a long tail with stretched magnetic field lines on the nightside that extends far antisunward, even beyond the Moon's orbit at $60 R_{E}$. It was found that the thin sheet of current flows in this magnetotail in the region where the magnetic field changes its direction (near-equatorial plane). This current divides the magnetotail into two regions with almost uniform magnetic field of opposite direction. Such structure was confirmed by numerous studies [e.g., Bame et al., 1967; Fairfield et al., 1979; Owen et al., 1995; Tsyganenko et al., 1998]. A special importance of the cross-tail current sheet comes from the fact that it is a region where instabilities arise leading to a magnetospheric substorm [e.g., Hones, 1979; Lui, 1991; Baker et al., 1996].

After coming to the magnetopause, the magnetotail current must flow somewhere further and Axford et al. [1965] realized that it closes via the magnetopause above and below the relatively strong magnetic field regions of the tail, forming a system in a shape of the Greek letter $\theta$, called a return current. Figure 3 presents the schematic view of the tail current with closure via return current on the magnetopause. The magnetic field above the equatorial current sheet is directed earthward and it is anti-earthward below the current sheet. Such configuration obviously produces a southward magnetic field at the Earth's location, which can compete in its strength with the magnetic field of the symmetric ring current during geomagnetic storms, at least during the early main phase [Maltsev, 2004]. Another intensively debatable question is how close the tail current comes to the Earth on the nightside while still being considered a tail current according to the conventional definition. Ganushkina et al. [2015] reviewed the existing definitions of the cross-tail current. Mainly, the tail current is defined as a nightside equatorial westward current outside 6.6 $R_{E}$, closing on the magnetopause, flowing in the region of the stretched magnetic field lines and isotropic plasma pressure, carried by particles with energies $<20 \mathrm{keV}$. Starting from early measurements [Ness, 1965; Speiser and Ness, 1967], the magnetic field in the near-Earth tail lobes was estimated as about $20 \mathrm{nT}$. For typical plasma sheet parameters of number density $n \sim 0.3 \mathrm{~cm}^{-3}$, ion temperature $T_{i} \sim 4.2 \mathrm{keV}$ and electron temperature 


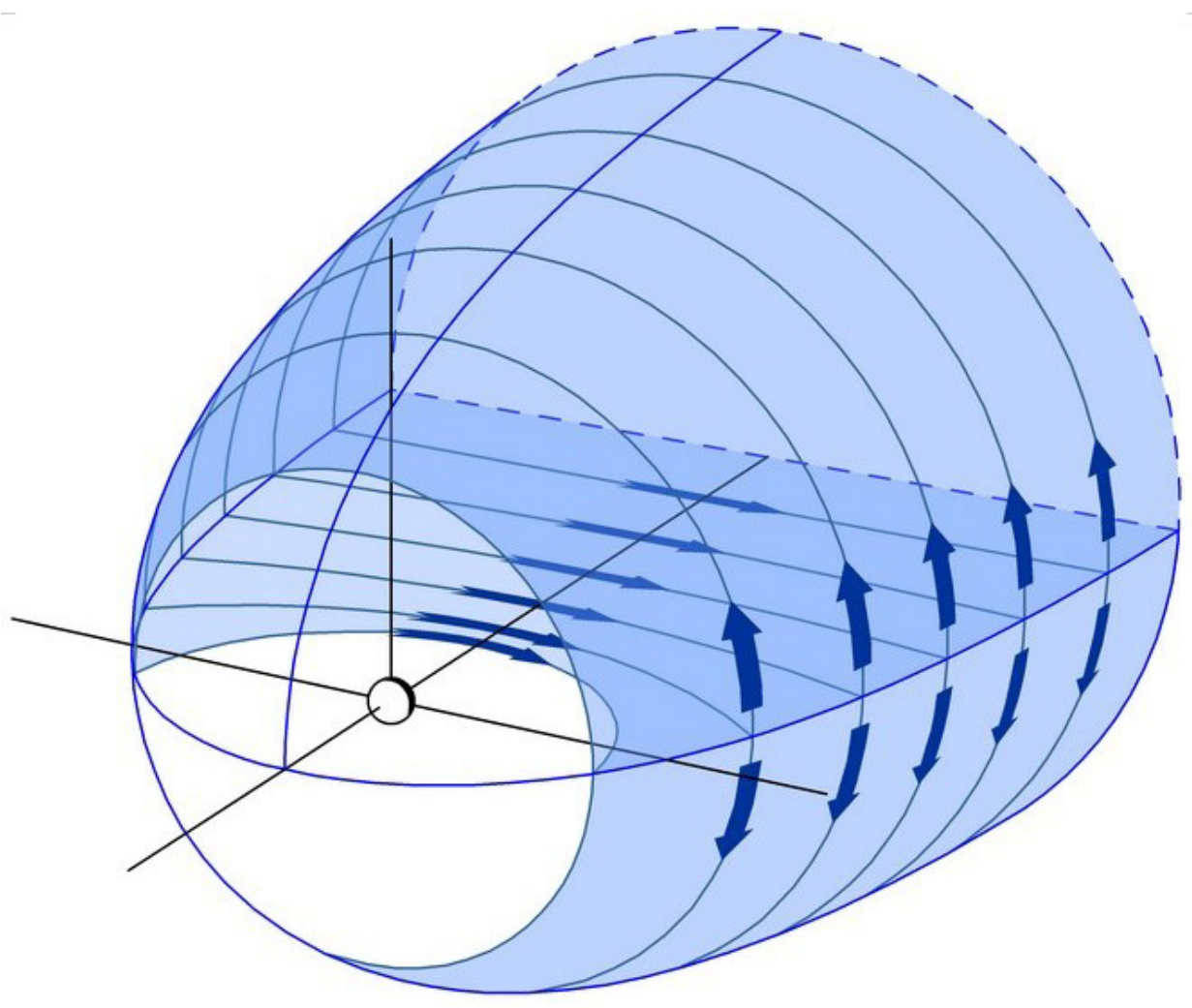

Figure 3. The tail current with closure via return current on magnetopause shown in light blue on the wire diagram of the magnetopause, as in Figure 2.

$T_{e} \sim 0.6 \mathrm{keV}$, the current density is $30 \mathrm{~mA} / \mathrm{m}$. If we take into account that the current sheet is long, the current density can be given as $30 \mathrm{~A} / \mathrm{km}$ or $2 \cdot 10^{5} \mathrm{~A} / R_{E}$ which means that $10^{6} \mathrm{~A}$ is carried in each of $5 R_{E}$ of the tail.

It should be mentioned that, although, on a global magnetopsheric scale, the tail current is the persistent and stable system, on a smaller scale it contains several very dynamic currents (e.g. dipolarization front currents [e.g., Liu et al., 2013] and small scale fieldaligned currents [e.g., Sergeev et al., 1996; Nakamura et al., 2001; Takada et al., 2008]).

\subsection{Region 1 Field-Aligned Currents}

Currents in the Earth's magnetosphere can flow not only perpendicular but also parallel to the magnetic field. These field-aligned currents were first suggested [Birkeland, 1908] to explain the variations of magnetic field measured on the ground in the polar regions and several theories were further developed [e.g., Alfvén, 1950; Fejer, 1961; 
Cole, 1963]. The measurements of the magnetic field onboard the low altitude polar orbiting Triad Satellite [Zmuda et al., 1966; Zmuda and Armstrong, 1974; Iijima and Potemra, 1976a] confirmed the existence of the current system of oppositely directed, but closely located concentric sheets. The Triad magnetometer provided three components of the magnetic field in the northern polar regions: (1) radially downward and nearly parallel to the main geomagnetic field; (2) transverse to the main geomagnetic field in the magnetic east-west direction; and (3) transverse to the main geomagnetic field in the magnetic north-south direction. Distinct variations with large amplitudes were observed mainly in the transverse east-west magnetic direction. These disturbances were observed at high invariant latitudes, between 60 and 80 degrees, statistically coincident with the visual auroral oval. When Triad was in the premidnight sector, the magnetic disturbances were in the eastward direction, whereas in the postmidnight sector, they were directed westward. The measured magnetic field was, first, increasing and, then descreasing, indicating the existence of the close, oppositely directed currents. If we use the right-hand rule for the observed magnetic field disturbances (see equation 2), our thumb will indicate the direction of the flowing current associated with these disturbances. To be consistent with the observed magnetic field variations, the current should flow along the magnetic field line (field-aligned current) and in the following pattern: away from the ionosphere in the poleward boundary of the magnetic disturbance region and into the ionosphere at the equatorward boundary in the pre-midnight sector; and in the direction into the ionosphere at the polar boundary and away from the ionosphere at the equator boundary in the postmidnight sector.

Iijima and Potemra [1976a] separated the field-aligned currents into Region 1 and Region 2 currents, where Region 1 currents were the poleward currents and Region 2 were the equatorward currents. Further from the Earth, the evidence of the existence of the field-aligned currents has been also found (see, for example, the review of Ganushkina et al. [2015] and references therein). Recently, the detailed maps of the field-aligned currents have been produced using the magnetic field measurements from the Iridium satellite constellation [e.g., Anderson et al., 2000, 2005] and later with the Iridium project upgrade to the Active Magnetosphere and Planetary Electrodynamics Response Experiment (AMPERE) [e.g., Clausen et al., 2012; Anderson et al., 2014; Coxon et al., 2014]. It was found that the current systems are much more structured and dynamic than the statistically derived current patterns of Iijima and Potemra [1976a]. The Region 1 current magnitudes 
from integrated AMPERE current distributions were found in the range from 0.1 MA to several MAs.

Field-aligned currents play an important role in the coupling between the magnetosphere and the ionosphere [e.g., Siscoe et al., 1991]. Figure 4 presents the schematic view of the Region 1 field-aligned currents. Part of the Region 1 currents is on open field lines and shown as connected to the dayside magnetopause in Figure 4 and it is driven by the solar wind, which acts as a generator [e.g., Iijima and Potemra, 1982; Stern, 1983; Siscoe et al., 1991; Xu and Kivelson, 1994; Cowley, 2000] possibly by dayside reconnection. The analogy was made with the action of a dynamo which is an electromotive force (emf) developed in a magnetic field around a circuit, part of which is in motion relative to the rest. As was demonstrated by Stern [1983], for an open magnetosphere, the circuit consists of two field lines, each with one end in the ionosphere and the other end in the solar wind. In the Earth's frame, the moving part of the circuit is the solar wind, and the current flow in the circuit is due to polarization drifts (see, for example, Figure 8 of Stern [1977]).

Another part of the Region 1 currents is on closed field lines and it is connected to the plasma sheet, boundary layer and the magnetopause on the nightside (Figure 4). The exact physical processes responsible for the formation of this nightside part of Region 1 field-aligned currents are still unclear. Their formation can be due to processes taking place in the boundary layer [e.g., Lotko et al., 1987; Ohtani et al., 1988] and in the plasma sheet [e.g., Ohtani et al., 1990; Antonova and Ganushkina, 1997; Wing and Newell, 2000; Xing et al., 2009]. Based on the magnetosphere-ionosphere current continuity, the fieldaligned current $j_{\|}$(positive if flowing into the ionosphere) is related to the magnetic field and plasma pressure in the magnetosphere [Grad, 1964; Vasyliunas, 1970; Tverskoy, 1982] as

$$
j_{\|}=\frac{B_{i}}{B_{e}} b \cdot(\nabla W \times \nabla P),
$$

where $W=\int \frac{d s}{B}$ is the magnetic flux tube volume, $d s$ is the element of magnetic field line length, $B$ is the magnetic field along the field line and the integration is taken between the two conjugate points, $P$ is the plasma pressure, $B_{i}$ and $B_{e}$ are the magnetic fields in the ionosphere and equatorial plane, respectively, $b$ is the magnetic field direction, and gradients are evaluated in the equatorial plane. The formation of a field-aligned current requires the existence of a hot plasma pressure gradient along the isosurfaces of the magnetic flux tube volume $W$, azimuthal plasma pressure gradient. The direction of this gra- 


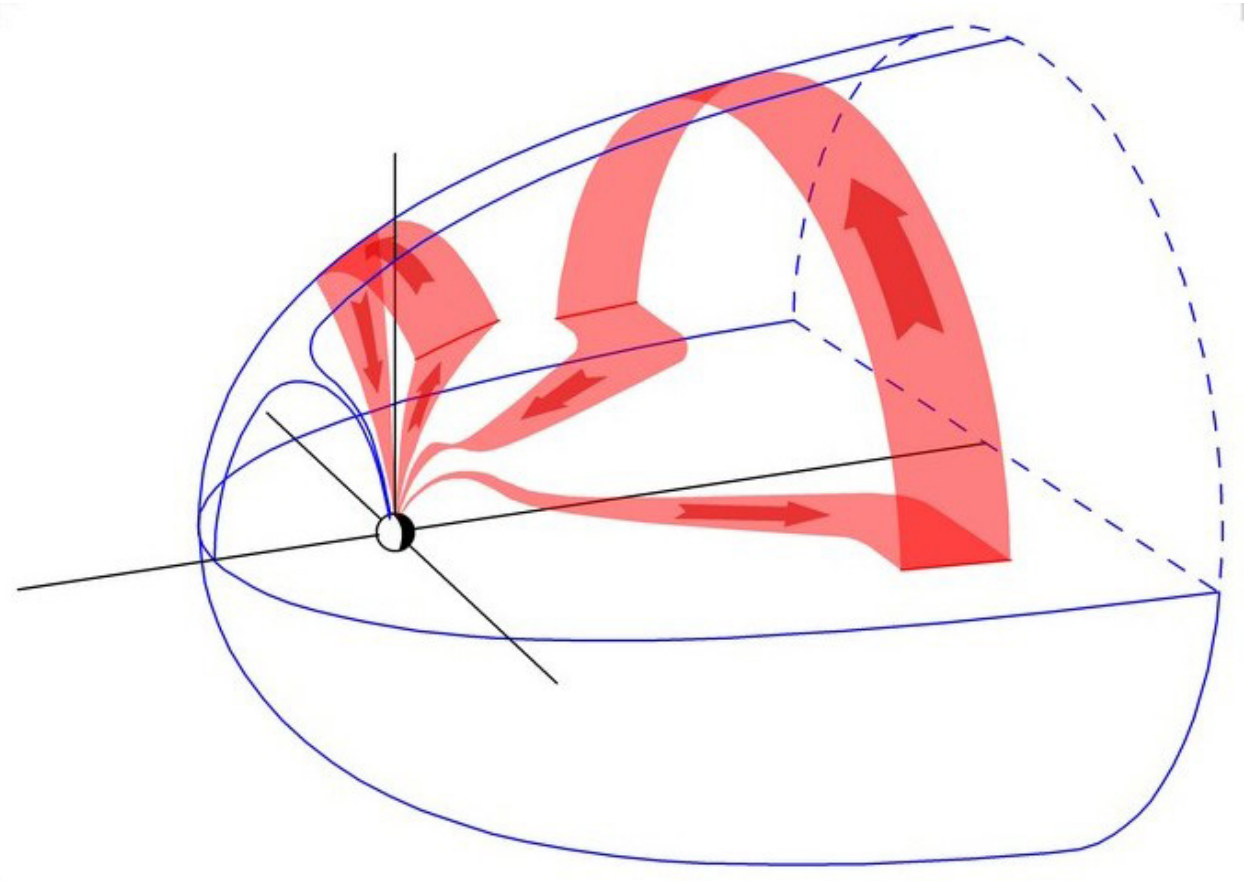

Figure 4. Region 1 field-aligned currents, shown as the red bands, including the two possible closure paths: directly to the magnetopause and via the far-tail plasma sheet.

dient determines the flow direction of the field-aligned current. If the azimuthal gradient is directed outward indicating that the pressure peaks are not around midnight but close to dawn and dusk, Region 1 field-aligned current can be generated in the plasma sheet. The presence of this gradient necessary for generation of the Region 1 field-aligned current in the plasma sheet was demonstrated by Antonova and Ganushkina [1997] based on modeling and by Xing et al. [2009] based on observations. That is, pressure gradients in the pre- and post-midnight sectors in general match the formation of Region 1 field aligned currents, as defined by Equation 5. So, at least some portion of Region 1 currents passes through the plasma sheet, as drawn in Figure 4.

\subsection{Symmetric ring current (eastward and westward) including cut ring currents on the dayside}

Early studies in magnetospheric physics introduced a current flowing around the Earth in the clockwise direction with the shape of a ring, or, rather, a toroid [Strmer, 1907; Schmidt, 1917]. The concept of this ring current played a significant role in the initial understanding of the geomagnetic storms [Chapman and Ferraro, 1931, 1941]. The 
current flowing around the Earth in the clockwise direction will depress the magnetic field at the Earth's surface, since the direction of its magnetic field is opposite to the Earth's internal magnetic field. The measured disturbances of the ground magnetic field during geomagnetic storms were attributed to the ring current increase and decrease [Akasofu and Chapman, 1961; Kamide and Fukushima, 1971; Kamide, 1974]. The early measurements of the ring current particles were made onboard the Orbiting Geophysical Observatory (OGO) 3 [e.g., Frank, 1967] and Explorer 45 [e.g., Smith and Hoffman, 1974] satellites. The first complete observational evidences of the ring current composition and structure came from the Active Magnetospheric Particle Tracer Explorers/Charge Composition Explorer (AMPTE/CCE) satellite which was in elliptical orbit with $9 R_{E}$ apogee. The obtained radial plasma pressure profiles in the magnetosphere contained pressure increasing Earthward with a peak around $3 R_{E}$ and then decreasing towards the Earth [Lui et al., 1987; Spence et al., 1989; Lui and Hamilton, 1992; De Michelis et al., 1997]. This feature is consistent with the two ring currents, one flowing around the Earth clockwise (westward) outside of the pressure peak and the other anticlockwise (eastward) inside of the pressure peak (see Equation 4 and Figure 1). Figure 5 presents the schematic view of the symmetric ring current. The light-brown current near the Earth flows eastward and the light-blue current flows westward. The derived current densities for the eastward ring current were typically about $2 \mathrm{nA} / \mathrm{m}^{2}$ whereas westward ring current can be of $\sim 1-4 \mathrm{nA} / \mathrm{m}^{2}$ during quiet times and of $\sim 7 \mathrm{nA} / \mathrm{m}^{2}$ during storm times but can be also as large as 50 $n A / m^{2}$ [e.g., Vallat et al., 2005]. The large-scale structure of the ring current was later confirmed by numerous studies. They include, for example, the analysis of the magnetic field data from the ISEE, AMPTE/CCE and Polar missions Le et al. [2004], and from the Combined Release and Radiation Effects Satellite (CRRES) [Jorgensen et al., 2004]; by the remote sensing of energetic neutral atoms (ENAs) emitted from the ring current from ISEE-1 spacecraft [Roelof, 1987] and Imager for Magnetopause-to-Aurora Global Exploration (IMAGE) and Two Wide-angle Imaging Neutral-atom Spectrometers (TWINS) missions [Pollock et al., 2001; Brandt et al., 2002; Buzulukova et al., 2010a; Goldstein et al., 2012]. The most recent Van Allen Probes mission provided extensive new observations of the ring current [e.g., Zhao et al., 2015, 2016; Gkioulidou et al., 2016; Kistler et al., 2016; Menz et al., 2017].

The traditional toroidal shape of the ring current has been questioned based on the fact that on the dayside there are two magnetic field minima above and below the equa- 


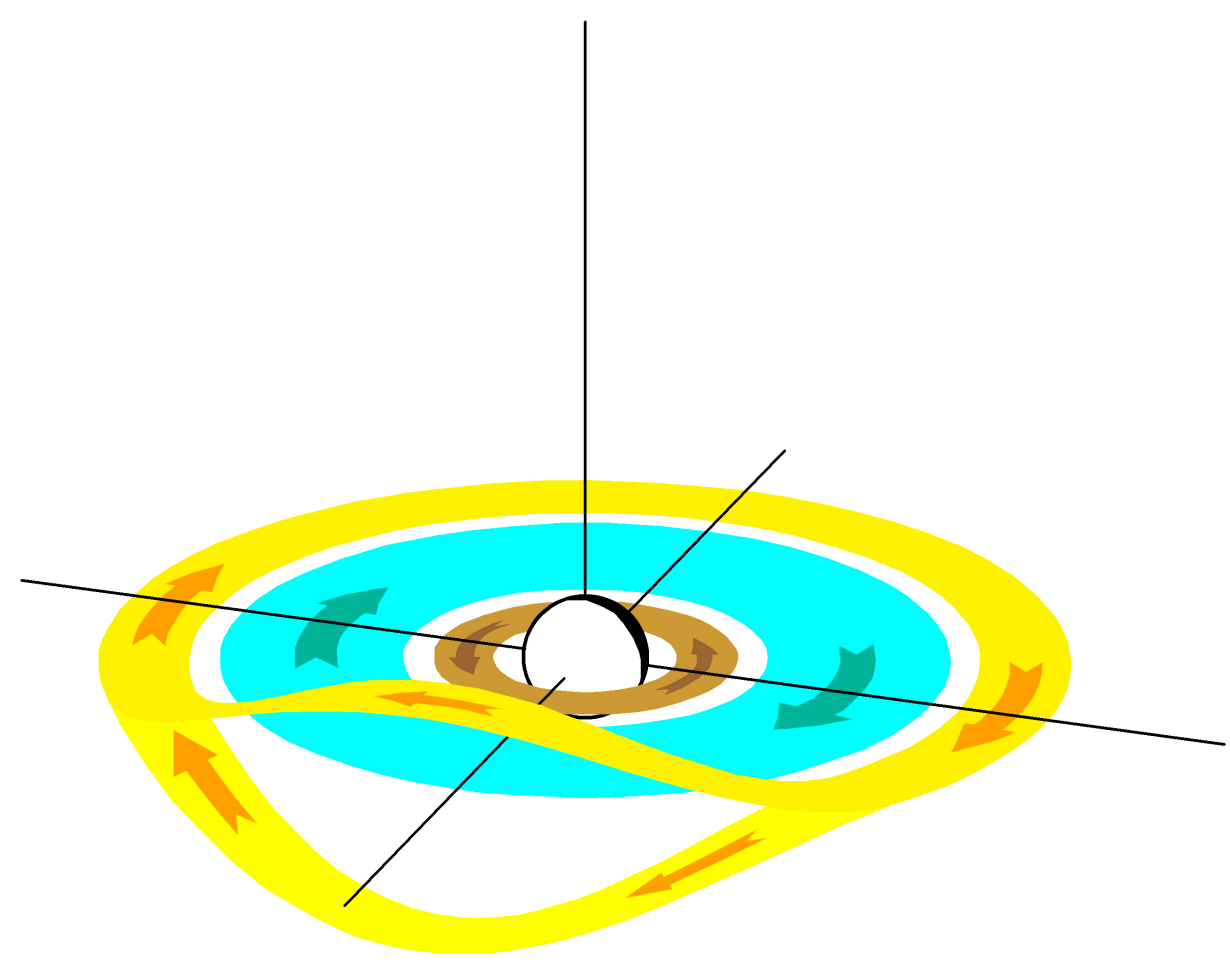

Figure 5. The symmetric ring current (eastward and westward, in brown and blue, respectively) including the cut ring currents on the dayside (in yellow). The viewing perspective is the same as in Figure 2 but now zoomed in closer to the Earth. 
torial plane. On the nightside, the magnetic field lines have only one minimum. This structure of the magnetic field determines the drift trajectories of particles. Antonova and Ganushkina [2000] and Antonova [2003, 2004] have suggested that the ring current does not go around the Earth as one system but splits into two branches in the dayside magnetosphere and forms the high-latitude continuation of the ordinary ring current. This current was named the cut-ring current (CRC). Figure 5 presents the schematic view of the cut ring current shown by the yellow ribbon. The initial verification of the existence of such a current was done by analyzing the radial profiles of plasma pressure gradients obtained from the THEMIS-B satellite data [Antonova et al., 2009] but an extensive analysis of the global plasma pressure distribution is still required.

The ring current system containing eastward and westward currents has been considered symmetric but from the observational point of view, the ring current is never purely symmetric [Jorgensen et al., 2004; Le et al., 2004]. This system is symmetric in a sense that all the current goes around the Earth and it is a closed system but it is almost always asymmetric in terms of the current density. The current density is not the same at the different locations around the Earth. It can be more symmetric during quiet times but during storm times it is asymmetric, especially during the storm peak [e.g., Liemohn et al., 2001]. The symmetry can be restored during storm recovery phase though not always fully [e.g., Ebihara and Ejiri, 2003; Kozyra and Liemohn, 2003; Daglis, 2006; Ganushkina et al., 2015].

\subsection{Partial Ring Current and Region 2 Field-Aligned Currents}

The magnetosphere itself is asymmetric due to solar wind-magnetosphere interactions resulting in the compression of the magnetic field lines on the dayside and stretching on the nightside. During disturbed times, more plasma is injected and transported from the nightside plasma sheet to the inner magnetosphere. Due to this process, the plasma pressure distribution in the inner magnetosphere becomes highly asymmetric with a gradient in the azimuthal direction which is reflected in the spatial asymmetry of the ring current. The concept of the partial ring current and its closure to the ionosphere was suggested by Alfvén in 1950s (see the review by Egeland and Burke [2012]). In-situ satellite observations showed a fairly symmetric ring current during geomagnetically quiet conditions and an asymmetric current distribution during storm times, symmetrizing again during the storm recovery phase [e.g., De Michelis et al., 1999; Korth et al., 2000; Ebihara et 
al., 2002; Lui, 2003; Le et al., 2004]. As was mentioned in Section 3.4, the westward ring current that the partial ring current is a part of can be as intense as $50 \mathrm{nA} / \mathrm{m}^{2}$ in current density.

The azimuthally localized perpendicular ring current cannot be closed in the inner magnetosphere. It must flow along a field line to complete a closure of the current [ $\mathrm{Va}$ syliunas, 1970; Wolf, 1970]. At the distances where partial ring current flows, the direction of azimuthal plasma pressure gradients is Earthward and slightly towards midnight, which corresponds to the generation of Region 2 field-aligned currents (Equation 5). According to the classification by Iijima and Potemra [1976a], they flow equatorward of the Region 1 currents, directed outward from the ionosphere near dawn and into the ionosphere around dusk. According AMPERE experiment [e.g., Coxon et al., 2014], the magnitudes of Region 2 field-aligned current are of several $M A$ but they tend to be smaller than Region 1 with the peak of the ratio between Region 1 and Region 2 being 1.15 . Observations of energetic neutral atoms (ENAs) emitted by a charge-exchange between energetic ring current ions and neutrals in the Earth's exosphere were successfully used for the reconstruction of the three-dimensional pressure distribution and the current systems related to the high pressure region [Roelof, 1989; Roelof et al., 2004; Roelof and Skinner, 2000; Brandt et al., 2004, 2008]. It was demonstrated that the partial ring current is connected to the Region 2 field-aligned currents. The theory of the generation of Region 2 field-aligned currents was also developed [Tverskoy, 1982; Heinemann, 1990; Heinemann and Pontius, 1991]. Figure 6 presents the schematic view of the partial ring current and its connection to the Region 2 field-aligned currents by purple-colored ribbon.

In Figure 6, one more current system is shown in orange and it is the so-called banana current [Liemohn et al., 2013a, 2015]. If the plasma pressure distribution is not symmetric (see Figure 1) and has a peak localized both radially and azimuthally, a magnetization current will flow around this peak. The banana current is the part of the current that flows around the localized pressure peak and accounts for all of the asymmetric eastward current. According to Liemohn et al. [2013a], the banana current can flow at 4-5 $R_{E}$ and be of several $M A$ during storm times but its intensity can drop to small numbers $(<0.1 M A)$ during extended quiet periods. Due to the decrease of the magnetic field with radial distance, the outer westward current is always larger than the eastward current, and this unbalanced magnetization current closes through the ionosphere as the partial ring 


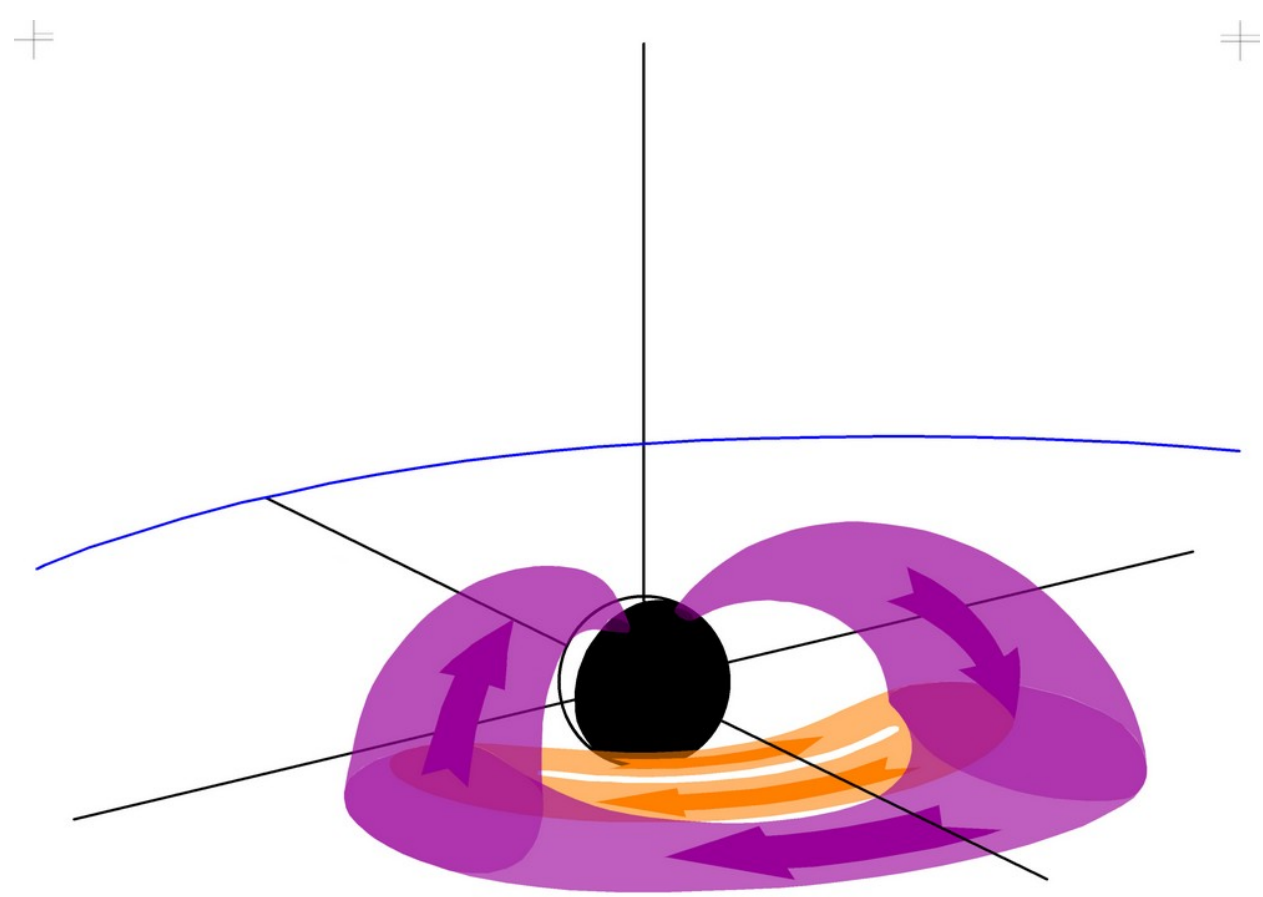

Figure 6. Region 2 field-aligned currents and partial ring current, shown in purple, and the banana current, shown in orange. The view here is shifted to be from the evening sector. 
current (see Equation 4 and Figure 1). This current system was noted by Roelof [1989] and Roelof et al. [2004] in current loop calculations derived from the ENA images.

\section{Dynamics of current systems}

Thus far, the focus has been on the static structure of geospace current systems. While this is useful to understand the general morphology of the magnetosphere and flow of electric current through near-Earth space, it is only the beginning of the story. The magnetosphere is highly susceptible to changes in the upstream solar wind conditions impinging on the system. A southward interplanetary magnetic field leads to dayside magnetic reconnection, erosion of the dayside magnetic field as it is opened and then moved over the polar caps to the nightside magnetosphere. This transfer results in a loading of the magnetotail lobes with additional magnetic flux, which increases the pressure on the plasma sheet. Eventually, magnetic reconnection occurs in the nightside as well, closing the field lines and allowing them to begin their transfer back to the dayside. This sunward return flow is also known as the $\mathbf{E} \times \mathbf{B}$ magnetospheric convection, driven by the magnetic pressure imbalance initially caused by the dayside reconnection with the IMF. This cycle, known as the Dungey cycle [Dungey et al., 1961], is associated with dramatic yet systematic changes in the current systems throughout the magnetosphere. It is useful to discuss the dynamics of current systems, at a very general and phenomenological level, as a function of geomagnetic activity. In the following sections, we present the main systematic dynamics of current systems most common in the magnetosphere.

\subsection{Interplay between dayside Chapman-Ferraro magnetopause currents and Region 1 field-aligned currents}

As the IMF turns southward (or becomes more intensely southward), the dayside magnetopause is eroded by magnetic reconnection. This stripping away of the dayside magnetic flux brings the magnetopause closer to Earth. The mapping of the magnetopause to its footpoints is, therefore, different, with the cusps shifted to more equatorward latitudes (see, for example, the recent study of Le et al. [2016]). This means that there is less surface area in the subsolar magnetopause region for the low-latitude eastward component of the Chapman-Ferraro currents. Moreover, transport of magnetic flux from the dayside to the nightside, along with flow increases in the high-latitude ionosphere, is associated with an increase in the Region 1 field-aligned current system. The net result is an increase 
in the size of the Region 1 system and a decrease in size of the Chapman-Ferraro current system. This change is shown in the two schematics presented in Figure 7.

The equatorward shift of the cusp regions and the decrease in spatial scale of the Chapman-Ferraro currents leads to a nonlinear feedback on the reconnection causing this situation. Siscoe et al. [2004] presented a study comparing four possible explanations of this internal limiting of the dayside reconnection rate. The first model suggests a weakening of the magnetic field near the reconnection site related to the enlarged Region 1 field-aligned currents, as first described by Hill et al. [1976] for the shape and dynamics of Mercury's magnetosphere. The second model hypothesized that the equatorward advancement of the cusps creates a dimple at the magnetopause [e.g., Raeder et al., 2001; Ober et al., 2006; Kivelson and Ridley, 2008] that limits the contact between the IMF and Earth's magnetic field. The third model envisions a change in the topology of the magnetopause and bow shock [e.g., Merkin et al., 2003, 2005], with the surfaces becoming flatter and farther from each other, allowing more room for the solar wind to flow around the planet, which alleviates pressure for reconnection. The fourth model invokes the $J \times B$ force from the Region 1 field-aligned currents to help balance the pressure of the incoming solar wind [Siscoe et al., 2002], moving the primary "point of impact" between the solar wind and magnetosphere away from the subsolar reconnection site. All four of these mechanisms relate to a growth of the Region 1 field-aligned current system and a shrinkage of the Chapman-Ferraro current loop, which is the scenario shown in Figure 7. The difference is that each has a slightly different aspect of that interplay which is the dominant cause of the nonlinearity.

Another way to think about this nonlinear negative feedback, and eventual saturation [e.g., Hairston et al., 2003] of the interaction, is with the scale size of the interaction region between the solar wind and magnetosphere. Burke et al. [1999] showed that, for moderate driving conditions, the interplanetary electric field scales linearly with the ionospheric cross polar cap electric potential difference, indicating that there is a characteristic width of the reconnection region on the dayside magnetopause of $\sim 4-5 R_{E}$. At more intense solar wind conditions, the nonlinear feedback becomes important and this scale size is systematically reduced. Others have also explored this scale size and reached a similar conclusion about the interaction region on the dayside magnetopause [e.g., Phan et al., 2001; Lopez et al., 2010; Lopez, 2016; Komar et al., 2015]. 

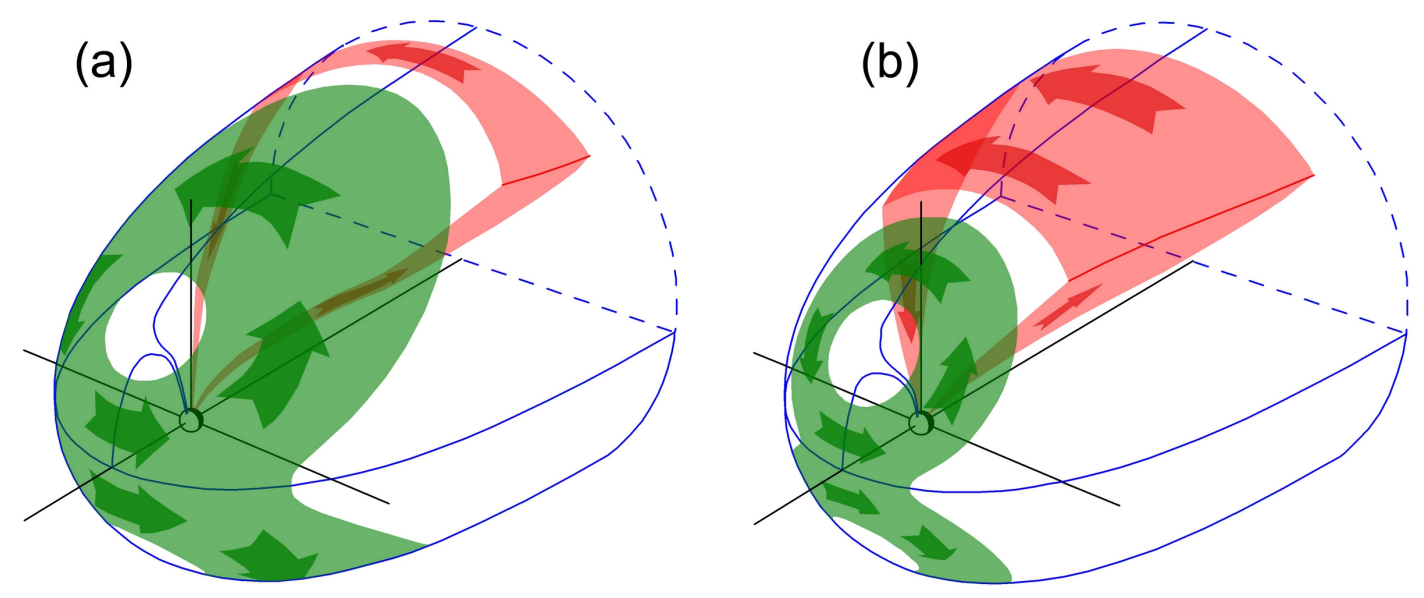

Figure 7. Interplay between dayside Chapman-Ferraro magnetopause currents and Region 1 field-aligned currents. As geomagnetic activity increases from (a) to (b), the Region 1 current system increases at the expense of the Chapman-Ferraro current system.

\subsection{Turning of IMF Bz from southward to northward: Region 1 and NBZ dayside field-aligned currents}

In addition to the Region 1 and Region 2 field-aligned currents, Iijima and Potemra [1976b] reported another large-scale field-aligned current system located at the noon sector poleward of the Region 1 current system. This current was called a cusp current since it is close to the magnetic cusp. Later, the most poleward dayside field-aligned current at noon oriented zonally and forming a pair with Region 1 current which is adjacent to it was called the Region 0 current [Iijima et al., 1978; Heikkila, 1984; Erlandson et al., 1988; Ohtani et al., 1995], and the current distributed inside the polar cap was called the NBZ current [Iijima et al., 1984]. The Region 0 current strongly depends on the IMF $B_{Y}$ component. In the northern hemisphere the Region 0 current flows mainly out of the ionosphere for positive IMF $B_{Y}$, and into the ionosphere for negative IMF $B_{Y}$. In some sense, the Region 0 current is not a separate current system, since it is always paired with the Region 1 current. At noon, both Region 0 and Region 1 currents are associated with the zonal convection driven by dayside reconnection off the noon meridian depending on the IMF orientation.

The NBZ current can be considered as a separate current system and it is very different from the Region 0 current. It was named as the NBZ current due to its appearance 

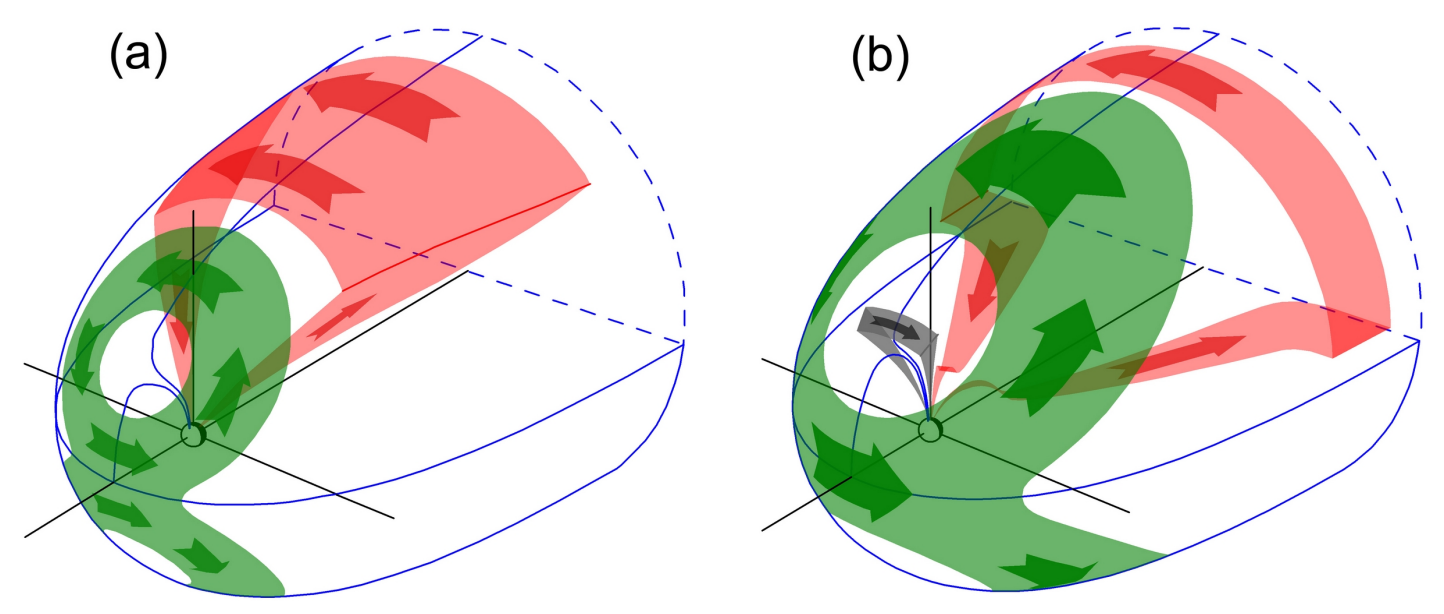

Figure 8. Turning of IMF Bz from southward to northward: the Region 1 and the NBZ dayside fieldaligned current system forms (gray ribbon), with the Chapman-Ferraro current expanding away from the cusp region and the Region 1 current system moving farther downtail.

during strong northward IMF $B_{z}$ [Iijima et al., 1984]. Figure 8a presents the Region 1 field-aligned current with the Chapman-Ferraro current during the absense of the strong northward IMF $B_{z}$ and Figure $8 \mathrm{~b}$ demonstrates the appearance of the NBZ dayside fieldaligned current system (gray ribbon). The NBZ current flows into and out of the ionosphere at dusk and at dawn, respectively. The NBZ system is related to the sunward convection in the middle of the polar cap during northward IMF $B_{Z}[$ Maezawa, 1976] and the reconnection between the IMF and the lobe magnetic field is considered as the most likely cause [Erlandson et al., 1988]. As it is shown in Figure 8b, the NBZ dayside field-aligned current system forms with the Chapman-Ferraro current expanding away from the cusp region and the Region 1 current system moving far downtail.

\subsection{Substorm current wedge development}

Magnetospheric substorms cause a strong magnetic field disturbance in the magnetosphere, especially on the nightside. The current system responsible for this disturbance was proposed in the early studies [Boström, 1964; Atkinson, 1967; Akasofu and Meng, 1969; Meng and Akasofu, 1969; Bonnevier et al., 1970; Rostoker et al., 1970; McPherron et al., 1973a,b; Clauer and McPherron, 1974] and called the Substorm Current Wedge (SCW). Figure 9 presents the schematic view of the SCW development. The SCW is 
thought of as a deviation of a part of the equatorial tail current (Figure 9a) to the ionosphere during the substorm with the downward field-aligned current on its dawn side and the upward current on the dusk side (Figure 9b). The direction of these field-aligned currents is the same as for the large scale Region 1 system (Section 3.3 and Figure 4).

The locations of the SCW's upward and downward currents coincide approximately with the west and east boundaries, respectively, of the auroral bulge which forms in the nightside auroral oval during substorm onset [e.g., Untiedt et al., 1978; Baumjohann et al., 1981; Sergeev et al., 1996]. The SCW is a very dynamic current system, it broadens azimuthally and radially after formation and fades with the substorm recovery [e.g., Nagai, 1982; Lopez and Lui, 1990; Jacquey et al., 1993; Ohtani et al., 1998]. The SCW can be localized entirely on the duskside or dawnside during the initial stage of the expansion phase [Bonnevier et al., 1970; Opgenoorth et al., 1980].

The SCW is a rather simplified representation of the current system associated with substorms. In reality, this system consists of multiple wedges with different scales and intensities as was shown by observational [e.g., Ohtani et al., 1990; Sergeev et al., 2011] and modelling [e.g., Birn et al., 1999; Yang et al., 2012; Birn and Hesse, 2013] studies. Moreover, the intensity of the secondary wedges can be significant and a SCW can be formed without the substorm development [Birn et al., 1999, 2004]. This complicated picture makes the exact definition of the SCW system a difficult task. Figure 9 is, therefore, a simplistic schematic showing the basic current closure path during the existence of SCW phenomenon.

\subsection{Storm-time transitions for tail, PRC, symmetric RC and Region 2 field-aligned currents}

The current systems in the near-Earth nightside region of the magnetosphere go through a systematic progression of intensity and location changes during magnetic storms. Figure 10 presents a schematic view of these storm-time transitions of the tail current, partial ring current, and symmetric ring current systems, using the color schemes of Section 3. The panel (a) shows a typical main phase configuration, the panel (b) is an illustration of current system locations near storm peak, and the panel (c) shows a typical recovery phase current system formation. 


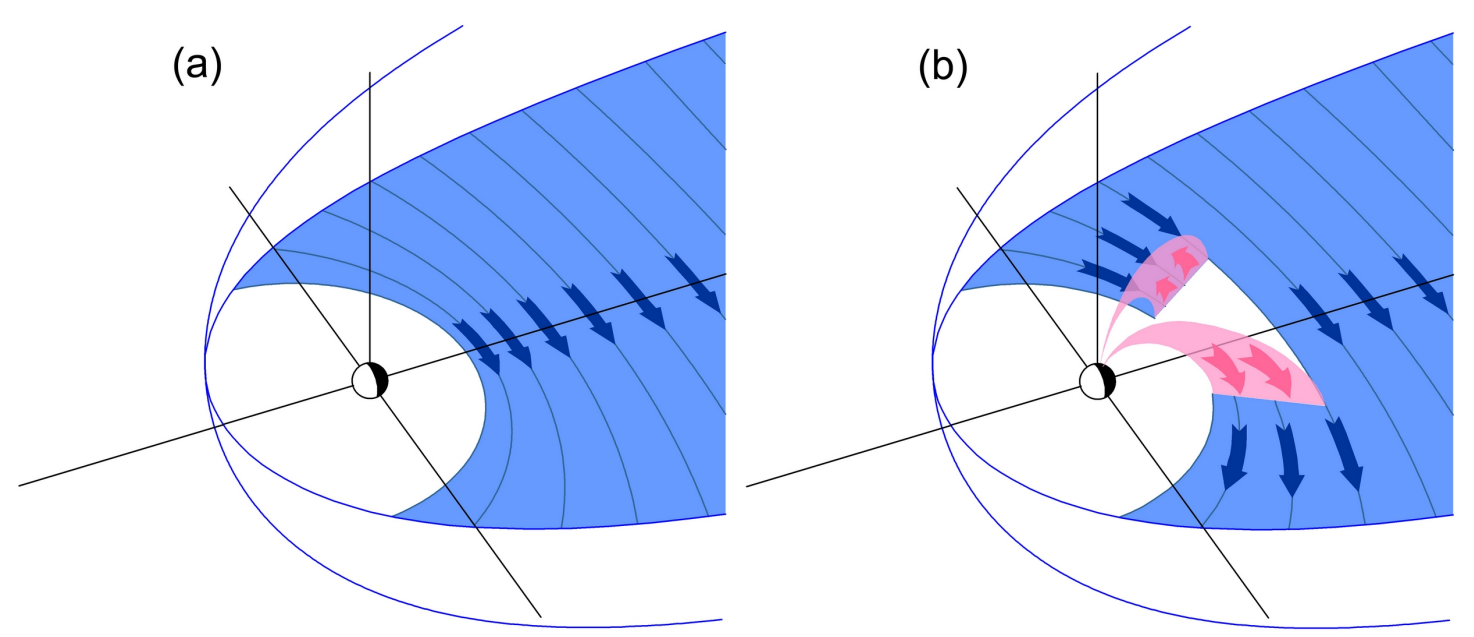

Figure 9. The substorm current wedge development, with the SCW field-aligned currents shown in pink diverting some of the tail current through the auroral zone ionosphere.

During a magnetic storm, hot charged particles move from the tail, through the inner magnetosphere, and out to the dayside magnetopause [e.g., Vasyliunas, 1970; Williams, 1987; Wolf et al., 1997; Daglis, 1999, 2001; Ebihara and Ejiri, 2003; Kozyra and Liemohn, 2003; Daglis, 2006; Wolf et al., 2007; Egeland and Burke, 2012; Ganushkina et al., 2015]. The current systems in this region change according to the variation in plasma pressure and magnetic field pressure (see Section 3.5). Quite a few studies have parsed the current in the near-Earth nightside magnetosphere into different current systems [Alexeev et al., 1996; Shi et al., 2008; Asikainen et al., 2010; Patra et al., 2011]. These studies, however, do not separate and distinguish contribution from the partial ring current, instead letting it be part of the symmetric ring current and tail current. Because the partial ring current is asymmetric like the tail current, it is most likely embedded within the tail current in these studies. The storm-time evolution of currents can be revealed using magnetospheric modeling since simultaneous in-situ measurements of all current systems are not possible. It was found that, initially, the tail current dominates the total current magnitude [Alexeev et al., 1996; Shi et al., 2008; Asikainen et al., 2010; Patra et al., 2011; Sitnov et al., 2010; Liemohn et al., 2013a; Stephens et al., 2013; Liemohn et al., 2015; Yang et al., 2015] as the geospace driving conditions start to ramp up and the hot particles in the plasma sheet begin to move sunward. The banana current then rises as the peak of the plasma pressure moves inward. Finally, the partial ring current develops into the dominant current system 
as the plasma pressure peak in the inner magnetosphere reaches very large values (tens of $\mathrm{nPa})$.

The relative intensity of the current systems depends on the exact pressure profile with radial distance and magnetic local time. In general, it goes like this. During the early main phase, there isn't much of a peak, so neither the partial ring current nor the banana current are very large, and the tail current dominates (Figure 10a). As the pressure starts to increase and the peak moves inward, the steep inner edge gradient and shallow outer slope gradient means that most of the non-tail westward current is closed via an eastward magnetospheric current around the plasma pressure peak, i.e., by a banana current. Therefore, the partial ring current remains relatively small during the early main phase and the banana current rivals the tail current in peak and/or integrated magnitude. Later in the main phase (Figure 10b), the plasma pressure peak moves even further inward, adiabatically energizing the plasma and creating steeper pressure gradients on the outer slope of the pressure crescent. Moreover, this inward shift puts the plasma pressure in a region where the magnetic field difference is larger between the inner and outer pressure gradient regions. Because of the $B^{-1}$ dependence of the cross-field current density, this larger magnetic field difference results in a proportionally larger increase in the westward asymmetric current density compared to the eastward current density. So, more of the westward current must close via field-aligned currents through the ionosphere, i.e., as partial ring current, instead of around the pressure peak as a banana current. Throughout all of this time, the symmetric ring current is relatively small because most particles are on open drift paths and the plasma pressure distribution is highly asymmetric. It is only in the late recovery phase (see Figure 10c) that the plasma pressure becomes relatively uniform in local time around the planet, merging the localized pressure peaks into one continuous pressure torus encircling Earth and giving rise to a strong westward symmetric ring current. A weaker eastward ring current is also produced in the inner pressure gradient slope.

\section{Synthesis}

The sections above discussed the usefulness of electric current system analysis and presented schematics of the large-scale configuration and dynamics of these systems. Below, these individual aspects of the geospace environment are brought together in a discussion about their impact on our understanding of magnetospheric physics and the challenges still remaining about current system analysis. 

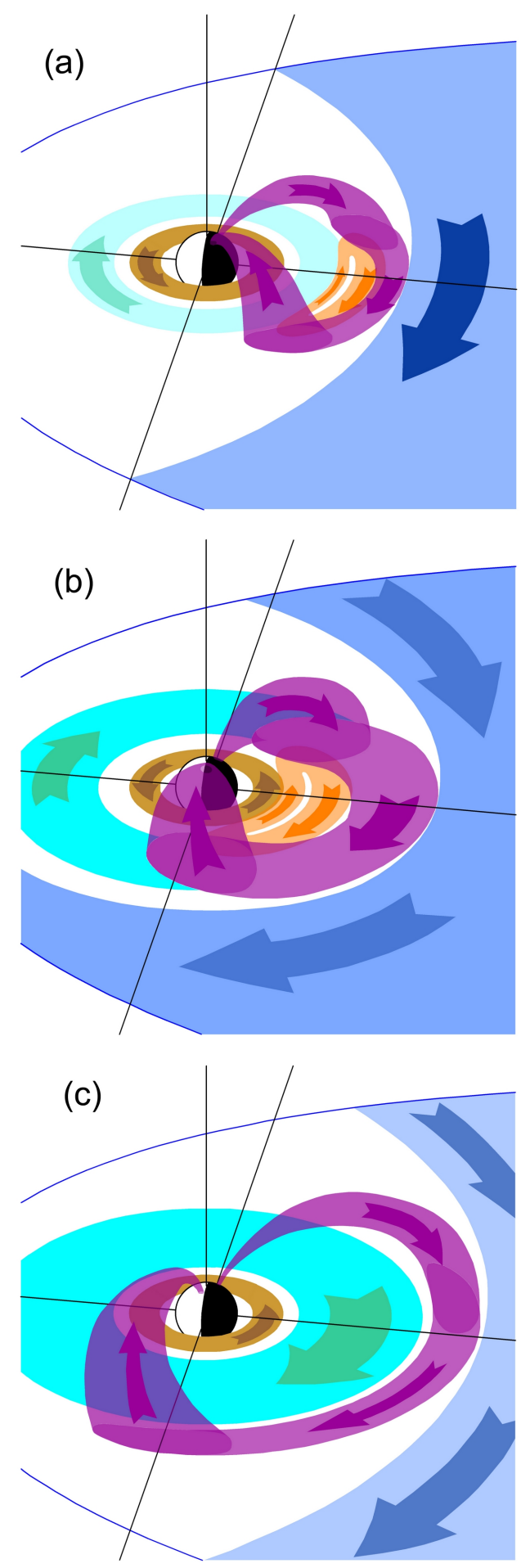

Figure 10. Storm-time transitions for the tail, banana, partial ring current, symmetric ring current and Region 2 field-aligned currents. 
Each current system has a magnetic field topology associated with it and its own influence on the geospace system. There are several current systems that pass through the ionosphere. These currents influence the electrostatic potential distribution in the ionosphere and, mapping along field lines, the magnetosphere. Field-aligned currents are often referred to in the classic definition of Region 1 and Region 2 Birkeland currents [Iijima and Potemra, 1976a]. In Figures 4 and 6 we showed the full current system loop that closes these field-aligned segments. These two current systems are particularly important because of this ionospheric segment and their connection to the intensity and pattern of the electric potential distribution. The Region 1 current system varies quickly and dramatically with IMF strength and orientation [e.g., Lockwood et al., 1990; Ridley et al., 1998], continually changing in its intensity and location relative to the dayside Chapman-Ferraro current system and the tail current system. The Region 2 current system, which closes the partial ring current loop, has a longer modification timescale [e.g., Horton et al., 2003, 2005; Ohtani and Uozumi, 2014] because of its relationship to plasma pressure distributions in the near-Earth plasma sheet and inner magnetosphere, and continually changes its intensity and location relative to the symmetric ring current and tail current systems. This mismatch in Region 1 and Region 2 field-aligned current response timescales leads to two phenomena: undershielding, manifested as a penetration of the high-latitude electric potential distribution down to low latitudes [e.g., Southwood and Wolf, 1978; Fejer et al., 1990; Fejer and Scherliess, 1997, 1998; Burke et al., 1998; Papitashvili et al., 1999; Ridley and Liemohn, 2002], which can dramatically change the equatorial ionosphere [e.g., Spiro et al., 1988; Abdu, 1997; Dabas et al., 2006; Mannucci et al., 2008, 2009]; and overshielding, most often associated with a supercorotation flow on the nightside [e.g., Pi et al., 2000; Peymirat et al., 2000; Wei et al., 2010] and the development of a predawn plasmaspheric shoulder [e.g., Goldstein et al., 2002, 2003; Liemohn et al., 2004; Huba and Sazykin, 2014]. The closure of the partial ring current is particularly important, since at certain times and places it flows into a region of low ionospheric conductance which results in relatively large electric fields. One such place is in the evening sector, where the downward current is equatorward of the main auroral oval of electron precipitation. The poleward closure of this current results in large poleward electric fields, driving sunward flows called Sub-Auroral Polarization Streams (SAPS) [Foster and Burke, 2002]. These strong flows rearrange the midlatitude ionosphere, creating storm enhanced density (SED) structures and perhaps supplying the high-latitude tongues of ionization and polar cap 
patches [e.g., Gonzales et al., 1978; Foster et al., 1998, 2007; Sojka et al., 2004; David et al., 2011]. This perturbation of the electric field pattern can become nonlinear as the hot particles in the magnetosphere respond to the changes with altered drift paths [e.g., Wolf, 1970; Fok et al., 2001; Liemohn et al., 2004, 2005, 2006]. This feedback loop can be weak or strong depending on the conductance in the ionospheric closure region and upstream driving conditions [e.g., Liemohn and Brandt., 2005; Zheng et al., 2006; Buzulukova et al., 2010b; Cramer et al., 2013; Katus et al., 2015] and depending on the intensity of the partial ring current system relative to other near-Earth nightside current loops.

The other current systems discussed above are purely magnetospheric in their closure path. Therefore they do not influence the electrostatic potential. They do, however, help shape the magnetosphere through their associated magnetic fields. The ChapmanFerraro current is directly connected to the dayside magnetospheric topology [e.g., Dungey et al., 1961; Siscoe et al., 2000], the tail current to the magnetotail lobe structure, and the banana current and eastward and westward symmetric ring current loops to the inflation of the dipole in the inner magnetosphere. The Region 1 and Region 2 current systems are at the transitions between these other loops, with the Region 1 loop in between the Chapman-Ferraro current system and the tail current system [e.g., Tanaka, 1995; Siscoe et al., 2002] and the Region 2 loop in between the tail current and the symmetric ring current [e.g., Iijima et al., 1990; Tsyganenko, 1995, 2000; Chun and Russell, 1997]. Understanding the relative strength and location of each electric current system is, therefore, vital to accurately predicting the variations of the magnetic field related to them and the associated space weather effects on satellites and on the ground. For instance, the inflation of the magnetic field corresponding to the near-Earth current systems such as the ring and tail currents alter the drift paths of the relativistic electrons changing the location and intensity of radiation belts. Energetic electrons trapped in the radiaiton belts are the major source of damaging space weather effects on satellites. Another example is the strength of Geomagnetically Induced Currents (GIC) on the ground determined by the horizontal geoelectric field which is controlled by the magnetospheric and ionospheric currents and by the Earth's conductivity. GIC can disrupt the transmission system operations with voltage collapse or damages of transformers.

Note that identification of specific current systems from in situ spacecraft measurements is difficult. As recently reviewed by Ganushkina et al. [2015], Liemohn et al. [2016], and Dunlop et al. [2016], there are several methods for calculating current density from 
spacecraft measurements. Taken alone, a current density value at a single point in the magnetosphere cannot be identified as part of a particular current system. Current density values at multiple locations must be synthesized into a regional or global scenario of possible current closure. Even this may not produce a unique current system pattern, and numerical models can help connect the localized current density values into a synoptic mapping of current flow through geospace.

On the other hand, the current constellation of satellites in the Heliophysics Great Observatory is relatively well-suited to address this issue. Specifically, there are several multi-spacecraft missions with both near-polar and near-equatorial elliptical orbits that provide, at certain times, the right distribution of measurements for global current system analysis. The Cluster mission [Escoubet et al., 2001] has four spacecraft in highinclination, $4 \times 19 R_{E}$ orbit, regularly passing through the inner magnetosphere, outer magnetosphere, and high-latitude magnetosphere for the past 16 years. The THEMIS mission [Angelopoulos et al., 2008; Sibeck and Angelopoulos, 2008], launched in 2007, originally had five spacecraft and now has three satellites in a highly elliptical low-inclination orbit ( $\sim 12 R_{E}$ apogee). This is complemented by two more low-inclination satellite sets, the two Van Allen Probes [Mauk et al., 2013; Stratton et al., 2013] in the inner magnetosphere, launched in late 2012 with an apogee of $5.7 R_{E}$, and the four MMS spacecraft [Burch et al., 2016; Fuselier et al., 2016], launched in early 2015 with an apogee of $~ 12$ $R_{E}$, eventually moving to $\sim 25 R_{E}$. These four sets of spacecraft have different precession rates and therefore change from similar local times of apogee, allowing for regional current system analysis, to vastly different local times, providing a global distribution of measurements for large-scale analysis. Another satellite constellation that is greatly contributing to our understanding of magnetospheric currents is the AMPERE, which uses the 66 commercial spacecraft of the Iridium constellation to produce field-aligned current maps every 10 minutes [Anderson et al., 2000, 2008; Clausen et al., 2012; Coxon et al., 2014]. While field-aligned current patterns and resulting ionospheric potential structures had been developed from the Defense Meteorological Satellite Program (DMSP) spacecraft measurements [e.g., Weimer et al., 1996], the high time cadence of spatial maps from the AMPERE program is a major step forward in sampling the high-latitude ionosphere. These low-Earth orbiting satellites provide a highly complementary data set to the magnetospheric missions, allowing for analysis of the current system connections and interplay between the ionosphere and magnetosphere. 
Empirical models have been developed that quantify the average structure and dynamics of current systems and magnetic fields in the magnetosphere [e.g., Mead and Fairfield, 1975; Tsyganenko, 1987, 1989, 1995; Hilmer and Voigt, 1995]. The schematics in this review largely follow the findings of these data-based functional algorithms of magnetospheric configuration. They are not particularly good, however, at matching the exact field configuration for any specific time during strong geomagnetic activity, and so several event-oriented versions of these codes have arisen [e.g., Ganushkina et al., 2002, 2004; Tsyganenko and Sitnov, 2005, 2007; Kubyshkina et al., 2008], yielding fairly accurate descriptions of the current systems during active times [e.g., Ganushkina et al., 2010; Stephens et al., 2016].

Numerical modeling has finally reached the accuracy levels needed for comprehensive global-scale current systems analysis. This has not been the case until recently. For example, Ganushkina et al. [2010] noted that the tail current was too weak in the Space Weather Modeling Framework (SWMF) simulation results for a magnetic storm. The accuracy and reliability of global magnetospheric models has been improving, though [cf., the data-model comparisons in Liemohn et al. [2011, 2013b]; Merkin et al. [2013], and several such global models are quite good at reproducing ground-based magnetometer perturbations [e.g., Pulkkinen et al., 2013; Rasttter et al., 2014]. While the comparisons are not perfect, several models have reached a level of robustness and accuracy to provide realistic magnetic topology variations throughout active times.

The time-varying nature of geospaces makes current system identification during highly disturbed intervals quite difficult. In fact, it could be that the concept of closure is violated on short timescales (i.e., minutes) and the schematic illustrations shown above are rather far from reality. During such times, the analysis should be limited to the regional level or to individual current segments.

\section{Final remarks}

We use the term current to describe a net flow of mass from one location to another. Similarly, an electric current is the net flow of charge from one location to another. While the basic concept is the same, the impact of electric currents is fundamentally different, because a net flow of electric charge has an associated magnetic field. That is, the forces 
are different, with far-reaching impacts because of the long-range nature of electromagnetic effects.

The review presented above covers the basic structure of electric current systems in Earth's magnetosphere and the typical time variation of these currents with geomagnetic activity. It should be pointed out that these schematics are just illustrations. They show the typical configuration and sequence of location changes during a storm interval. The actual current systems of the inner magnetosphere could be much more complicated, with multiple pressure peaks leading to many small-scale current systems. The Earth's magnetosphere is dominated by two elements: the internal dipolar magnetic field and the interplanetary magnetic field from the Sun. Everywhere that the IMF distorts the Earth's dipole, there is an electric current flowing. As the IMF changes from its typical eclipticplane configuration to a more southward orientation, a direction that causes magnetic reconnection and energy transfer to the magnetosphere, the magnetic field topology changes and the associated current systems must also change. Through many studies over the past five decades, this structure and dynamics of the magnetic field and corresponding current systems have come to be understood. The above presentation compiles this understanding into a set of schematic illustrations depicting the standard configurations and expected transitions with geomagnetic activity.

While it is very difficult to distinguish these current systems from single-point spacecraft measurements, a constellation of craft could provide the necessary observations to identify and classify local current density values into large-scale current systems. Such a constellation exists now, with numerous near-equatorial-plane satellites in the Heliophysics Great Observatory right now, including the Van Allen Probes, THEMIS, and MMS. Furthermore, low-Earth-orbit satellites, such as the DMSP fleet and the AMPERE project, provide the best-ever measure of field-aligned currents and magnetosphere-ionosphere electrodynamic coupling. Finally, numerical modeling has reached a maturity level to accurately simulate the state of the magnetosphere, even during highly disturbed intervals, providing a synoptic view of the magnetic field topology and current system configuration on a global scale. Understanding current system structure and evolution allows us to better predict the geospace consequences of a developing space storm, as well as to better prepare for and mitigate the possible space weather hazards arising from this activity. 


\section{Acknowledgments}

The projects leading to these results have received funding from the European Union Seventh Framework Programme (FP7/2007-2013) under grant agreement No 606716 SPACESTORM and from the European Union's Horizon 2020 research and innovation program under grant agreement No 637302 PROGRESS. Work in the US was conducted under NASA grants NNX14AF34G, NNX17AI48G, NNX17AB87G, 80NSSC17K0015, and NNX14AC02G. N. Ganushkina and M. Liemohn thank the International Space Science Institute in Bern, Switzerland, for their support of the international teams on "Resolving Current Systems in Geospace", "Analysis of Cluster Inner Magnetosphere Campaign data, in application of the dynamics of waves and wave-particle interaction within the outer radiation belt" and "Ring current modeling: Uncommon Assumptions and Common Misconceptions". No original data were used or produced in this paper, all data is cited in the reference list.

\section{References}

Abdu, M. A. (1997), Major phenomena of the equatorial ionosphere-thermosphere system under disturbed conditions, J. Atmos. Sol. Terr. Phys., 59(13), 1505-1519, doi:10.1016/S1364-6826(96)00152-6.

Akasofu, S.-I. (1984), The magnetospheric currents: An introduction, in Magnetospheric Currents, Geophys. Monogr. Series., vol. 28, edited by T. A. Potemra, pp. 29-48, Am. Geophys. Union, Washington, D.C., doi: 10.1029/GM028p0029.

Akasofu, S.-I. and Chapman, S. (1961), The Ring Current, Geomagnetic Disturbance, and the Van Allen Radiation Belts, J. Geophys. Res., 66, 1321-1350.

Akasofu, S.-I., and C.-I. Meng (1969), A study of polar magnetic substorms, J. Geophys. Res., 74(1), 293-313, doi:10.1029/JA074i001p00293.

Alexeev, I. I., E. S. Belenkaya, V. V. Kalegaev, Y. I. Feldstein, and A. Grafe (1996), Magnetic storms and magnetotail currents, J. Geophys. Res., 101(A4), 7737-7747, doi:10.1029/95JA03509.

Alfvén, H. (1950), Discussion of the Origin of the Terrestrial and Solar Magnetic Fields, Tellus, 2, 74-82.

Anderson, B. J., K. Takahashi, B. A. Toth (2000), Sensing global Birkeland currents with Iridium engineering magnetometer data, Geophys. Res. Lett., 27, 4045-4048, doi: 
10.1029/2000GL000094.

Anderson, B. J., S.-I. Ohtani, H. Korth, and A. Ukhorskiy (2005), Storm time dawndusk asymmetry of the large-scale Birkeland currents, J. Geophys. Res., 110, A12220, doi:10.1029/2005JA011246.

Anderson, B. J., H. Korth, C. L. Waters, D. L. Green, and P. Stauning (2008), Statistical Birkeland current distributions from magnetic field observations by the Iridium constellation, Ann. Geophys., 26, 671-687, doi:10.5194/angeo-26-671-2008.

Anderson, B. J., H. Korth, C. L. Waters, D. L. Green, V. G. Merkin, R. J. Barnes, and L. P. Dyrud (2014), Development of large-scale Birkeland currents determined from the Active Magnetosphere and Planetary Electrodynamics Response Experiment, Geophys. Res. Lett., 41, 3017-3025, doi:10.1002/2014GL059941.

Angelopoulos, V. (2008), The THEMIS mission, Space Sci. Rev., 141, 5-34, doi:10.1007/s11214-008-9336-1.

Antonova, E. E. (2003), Investigation of the hot plasma pressure gradients and the configuration of magnetospheric currents from INTERBALL, Adv. Space Res., 31(5), 11571166.

Antonova, E. E. (2004), Magnetostatic equilibrium and current systems in the Earth's magnetosphere, Adv. Space Res., 33(5), 752-760.

Antonova, E. E., and N. Yu. Ganushkina (1997), Azimuthal hot plasma pressure gradients and dawn-dusk electric field formation, J. Atmos. Terr. Phys., 59, 1343-1354.

Antonova, E. E. and N. Yu. Ganushkina (2000), Inner magnetospheric currents and their role in the magnetosphere dynamics, Phys. Chem. Earth (C), 25(1-2), 23-26.

Antonova E. E., I. P. Kirpichev, I. L. Ovchinnikov, K. G. Orlova, and M. V. Stepanova (2009), High latitude magnetospheric topology and magnetospheric substorm, Ann. Geophys., 27, 4069-4073.

Asikainen, T., V. Maliniemi, and K. Mursula (2010), Modeling the contributions of ring, tail, and magnetopause currents to the corrected Dst index, J. Geophys. Res., 115, A12203, doi:10.1029/2010JA015774.

Atkinson, G. (1967), Polar magnetic substorms, J. Geophys. Res., 72(5), 1491-1494, doi:10.1029/JZ072i005p01491.

Axford, W. I., H. E. Petschek, and G. L. Siscoe (1965), Tail of the magnetosphere, J. Geophys. Res., 70(5), 1231-1236, doi:10.1029/JZ070i005p01231. 
Baker, D. N., T. I. Pulkkinen, V. Angelopoulos, W. Baumjohann, and R. L. McPherron (1996), Neutral line model of substorms: Past results and present view, J. Geophys. Res., 101(A6), 12975-13010, doi:10.1029/95JA03753.

Bame, S. J., J. R. Asbridge, H. E. Felthauser, E. W. Hones, and I. B. Strong (1967), Characteristics of the plasma sheet in the Earth's magnetotail, J. Geophys. Res., 72(1), 113129, doi:10.1029/JZ072i001p00113.

Baumjohann, W., R. J. Pellinen, H. J. Opgenoorth, E. Nielsen (1981), Joint twodimensional obervations of ground magnetic and ionospheric electric fields associated with the auroral zone currents: Current systems associated with local auroral breakups, Planet. Space Sci., 29, 431.

Bering III, E. A. (1995), The global circuit: Global thermometer, weather by-product or climatic modulator?, Rev. Geophys., 33(S2), 845-862, doi:10.1029/95RG00549.

Bierkens, M. F. P. (2015), Global hydrology 2015: State, trends, and directions, Water Resour. Res., 51, 4923-4947, doi:10.1002/2015WR017173.

Birkeland, Kr. (1908), The Norwegian Aurora Polaris Expedition 1902-1903, 1, On the Cause of Magnetic Storms and the Origin of Terrestrial Magnetism, first section, H. Aschehoug and Co., Christiania.

Birkeland, K. (1913), The Norwegian Aurora Polaris Expedition, 1902-1903, vol. 1, 2nd section, Aschehoug, Christiana.

Birn, J., and M. Hesse (2013), The substorm current wedge in MHD simulations, J. Geophys. Res. Space Physics, 118, 3364-3376, doi:10.1002/jgra.50187.

Birn, J., M. Hesse, G. Haerendel, W. Baumjohann, and K. Shiokawa (1999), Flow braking and the substorm current wedge, J. Geophys. Res., 104(A9), 19895-19903, doi:10.1029/1999JA900173.

Birn, J., Raeder, J., Wang, Y. L., Wolf, R. A., and Hesse, M. (2004), On the propagation of bubbles in the geomagnetic tail, Ann. Geophys., 22, 1773-1786, doi:10.5194/angeo22-1773-2004.

Bonnevier, B., R. Boström, and G. Rostoker (1970), A three-dimensional model current system for polar magnetic substorms, J. Geophys. Res., 75(1), 107-122, doi:10.1029/JA075i001p00107.

Boström, R. (1964), A model of the auroral electrojets, J. Geophys. Res., 69(23), 49834999, doi:10.1029/JZ069i023p04983. 
Brandt, P. C., P.S. Ohtani, D.G. Mitchell, M.-C. Fok, E.C. Roelof, R. DeMajistre (2002), Global ENA observations of the storm mainphase ring current: implications for skewed electric fields in the inner magnetosphere, Geophys. Res. Lett., 29(20), 1954.

Brandt P. C., Roelof, E. C., Ohtani, S., Mitchell, D. G., and Anderson, B. (2004), IMAGE/HENA: pressure and current distributions during the 1 October 2002 storm, Adv. Space Res., 33, 719-722.

Brandt, P. C., Zheng, Y., Sotirelis, T. S., Oksavik, K., and Rich, F. J. (2008), The linkage between the ring current and the ionosphere system, in: Midlatitude ionospheric $d y$ namics and disturbances, Geophys. Monog. Series, vol. 181, edited by Kintner, P. M., Coster, A. J., Fuller-Rowell, T., Mannucci, A. J., Mendillo, M., and Heelis, R., pp. 135143.

Burch, J. L., T. E. Moore, R. B. Torbert, and B. L. Giles (2016), Magnetospheric Multiscale Overview and Science Objectives, Space Sci.Rev., 199, 5-21, doi: 10.1007/s11214-015-0164-9.

Burke, W. J., N. C. Maynard, M. P. Hagan, R. A. Wolf, G. R. Wilson, L. C. Gentile, M. S. Gussenhoven, C. Y. Huang, T. W. Garner, and F. J. Rich (1998), Electrodynamics of the inner magnetosphere observed in the dusk sector by CRESS and DMSP during the magnetic storm of June 4-6, 1991, J. Geophys. Res., 103, $29,399$.

Burke, W. J., D. R. Weimer, and N. C. Maynard (1999), Geoeffective interplanetary scale sizes derived from regression analysis of polar cap potentials, J. Geophys. Res., 104(A5), 9989-9994, doi:10.1029/1999JA900031.

Buzulukova, N., M.-C. Fok, J. Goldstein, P. Valek, D. McComas, P.C. Brandt (2010a), Ring current dynamics in modest and strong storms: comparative analysis of TWINS and IMAGE/HENA data with CRCM, J. Geophys. Res., 115, 12234, doi:10.1029/2010JA015292.

Buzulukova, N., M.-C. Fok, A. Pulkkinen, M. Kuznetsova, T. E. Moore, A. Glocer, P. C. Brandt, G. Tóth, and L. Rastätter (2010b), Dynamics of ring current and electric fields in the inner magnetosphere during disturbed periods: CRCM-BATS-R-US coupled model, J. Geophys. Res., 115, A05210, doi:10.1029/2009JA014621.

Cahill, L. J., and P. G. Amazeen (1963), The boundary of the geomagnetic field, J. Geophys. Res., 68, 1835.

Carrington, R. C. (1860), Description of a singular appearance seen in the Sun on September 1, 1859, Mon. Not. Roy. Astron. Soc., 20, 13-14. 
Chapman, S. and V. C. A. Ferraro (1931), A new theory of magnetic storms, Terr. Mag., 36, 77-97.

Chapman S. and V. C. A. Ferraro (1941), The geomagnetic ring-current: Its radial stability, Terr. Mag., 46, 1-6.

Chun, F. K., and C. T. Russell (1997), Field aligned currents in the inner magnetosphere: Control by geomagnetic activity, J. Geophys. Res., 102, 2261.

Clauer, C. R. and R. L. McPherron (1974), Mapping the local time-universal time development of magnetospheric substorms using mid-Latitude magnetic observations, J. Geophys. Res., 79(19), 2811-2820.

Clausen, L. B. N., J. B. H. Baker, J. M. Ruohoniemi, S. E. Milan, and B. J. Anderson (2012), Dynamics of the region 1 Birkeland current oval derived from the Active Magnetosphere and Planetary Electrodynamics Response Experiment (AMPERE), J. Geophys. Res., 117, A06233, doi:10.1029/2012JA017666.

Cole, K. D. (1963), Motions of the aurora and radio-aurora and their relationships to ionospheric currents, Planet. Space Sci., 10, 129-163.

Coroniti, F. V., and C. F. Kennel (1972), Changes in magnetospheric configuration during the substorm growth phase, J. Geophys. Res., 77, 3361-3370.

Cowley, S. W. H. (2000), Magnetosphere-ionosphere interactions: a tutorial review, in Magnetospheric Current Systems, Geophysical Monograph 118, AGU.

Coxon, J. C., S. E. Milan, L. B. N. Clausen, B. J. Anderson, and H. Korth (2014), The magnitudes of the regions 1 and 2 Birkeland currents observed by AMPERE and their role in solar wind-magnetosphere-ionosphere coupling, J. Geophys. Res., 119, 98049815, doi: 10.1002/2014JA020138.

Cramer, W. D., N. E. Turner, M.-C. Fok, and N. Y. Buzulukova (2013), Effects of different geomagnetic storm drivers on the ring current: CRCM results, J. Geophys. Res. Space Physics, 118, doi:10.1002/jgra.50138.

Dabas, R. S., R. M. Das, V. K. Vohra, and C. V. Devasia (2006), Space weather impact on the equatorial and low latitude F-region ionosphere over India, Ann. Geophys., 24, 97-105.

Daglis, I.A. (2001), The storm-time ring current, Space Sci. Rev. 98, 343-363.

Daglis, I. A. (2006), Ring Current Dynamics, Space Sci. Rev., 124, 1-4, 183, DOI: 10.1007/s11214-006-9104-z. 
Daglis, I. A., R. M. Thorne, W. Baumjohann, and S. Orsini (1999), The terrestrial ring current current: Origin, formation, and decay, Rev. Geophys., 37, 407-438.

David, M., J.J. Sojka, R.W. Schunk, M.W. Liemohn, A.J. Coster (2011), Dayside midlatitude ionospheric response to storm-time electric fields, J. Geophys. Res., 116, A12302, doi: 10.1029/2011JA016988.

De Michelis, P., I. A. Daglis, and G. Consolini (1997), Average terrestrial ring current derived from AMPTE/CCE-CHEM measurements, J. Geophys. Res., 102, 14,103-14,111.

De Michelis, P., I. A. Daglis, and G. Consolini (1999), An average image of proton plasma pressure and of current systems in the equatorial plane derived from AMPTE/CCE-CHEM measurements, J. Geophys. Res., 104, 28615-28624, doi:10.1029/1999JA900310.

Dijkstra, H. A., and M. Ghil (2005), Low-frequency variability of the large-scale ocean circulation: A dynamical systems approach, Rev. Geophys., 43, RG3002, doi:10.1029/2002RG000122.

Dungey, J. W. (1961), Interplanetary magnetic field and auroral zones, Phys. Rev. Lett., 6, 47-49.

Dunlop, M. W., S. Haaland, P. C. Escoubet, and X.-C. Dong (2016), Commentary on accessing 3-D currents in space: Experiences from Cluster, J. Geophys. Res. Space Physics, 121, 7881-7886, doi:10.1002/2016JA022668.

Ebihara, Y. and Ejiri, M. (2003), Numerical simulation of the ring current: Review, Space Sci. Rev., 105, 377, doi:10.1023/A:1023905607888

Ebihara, Y., Ejiri, M., Nilsson, H., Sandahl, I., Milillo, A., Grande, M., Fennell, J. F., and Roeder, J. L. (2002), Statistical distribution of the storm-time proton ring current: POLAR measurements, Geophys. Res. Lett., 29, 1969, doi:10.1029/2002GL015430.

Egeland, A., and W. J. Burke (2012), The ring current: a short biography, Hist. Geo Space Sci., 3, 131-142.

Egger, J., K. Weickmann, and K.-P. Hoinka (2007), Angular momentum in the global atmospheric circulation, Rev. Geophys., 45, RG4007, doi:10.1029/2006RG000213.

Emanuel, K. A., David Neelin, J. and Bretherton, C. S. (1994), On large-scale circulations in convecting atmospheres, Q.J.R. Meteorol. Soc., 120, 1111-1143, doi:10.1002/qj.49712051902.

Erlandson, R. E., L. J. Zanetti, T. A. Potemra, P. F. Bythrow, and R. Lundin, IMF By Dependence of Region 1 Birkeland Currents Near Noon, J. Geophys. Res., 93(A9), 9804- 
9814, doi:10.1029/JA093iA09p09804, 1988.

Escoubet, C. P., M. Fehringer, and M. Goldstein (2001), Introduction: The Cluster mission, Ann. Geophys., 19, 1197-1200.

Fairfield, D. H. (1977), Electric and magnetic fields in the high-latitude magnetosphere, Rev. Geophys., 15(3), 285-298, doi:10.1029/RG015i003p00285.

Fairfield, D. H. (1979), On the average configuraton of the geomagnetic tail, J. Geophys. Res., 84(A5), 1950-1958, doi:10.1029/JA084iA05p01950.

Fan, Y. (2015), Groundwater in the Earth's critical zone: Relevance to large-scale patterns and processes, Water Resour. Res., 51, 3052-3069, doi:10.1002/2015WR017037.

Fejer, J. A. (1961), The effects of energetic trapped particles on magnetospheric motions and ionospheric currents, Can. J. Phys., 39, 1409.

Fejer, B. G., and L. Scherliess (1997), Empirical models of storm time equatorial zonal electric fields, J. Geophys. Res., 102, 24,047.

Fejer, B. G., and L. Scherliess (1998), Mid- and low-latitude prompt-penetration ionospheric zonal plasma drifts, Geophys. Res. Lett., 25, 3071.

Fejer, B. G., R. W. Spiro, R. A. Wolf, and J. C. Foster (1990), Latitudinal variation of perturbation electric fields during magnetically disturbed periods: 1986 SUNDIAL observations and model results, Ann. Geophys., 8, 441.

Fok M.-C., R. A. Wolf, R. W. Spiro, T. E. Moore (2001), Comprehensive computational model of the Earth's ring current, J. Geophys. Res. 106, 8417-8424.

Foster, J. C., W. J. Burke (2002), SAPS: A new categorization of subauroral electric fields, Eos Trans, AGU. 83(36), 393.

Foster, J. C., S. Cummer, and U. S. Inan (1998), Midlatitude particle and electric field effects at the onset of the November 1993 geomagnetic storm, J. Geophys. Res., 103, 26,359 .

Foster, J. C., W. Rideout, B. Sandel, W. T. Forrester, and F. J. Rich (2007), On the relationship of SAPS to storm-enhanced density, J. Atmos. Sol. Terr. Phys., 69, 303-313.

Frank, L. A. (1967), Several observations of low-energy protons and electrons in the Earth's magnetosphere with OGO 3, J. Geophys. Res., 72(7), 1905-1916, doi:10.1029/JZ072i007p01905.

Fuselier, S. A., W. S. Lewis, C. Schiff, R. Ergun, J. L. Burch, S. M. Petrinec, and K. J. Trattner (2016), Magnetospheric Multiscale science mission profile and operations, Space Sci. Rev., 199, 77-103, doi: 10.1007/s11214-014-0087-x. 
Ganushkina, N. Y., T. I. Pulkkinen, M. V. Kubyshkina, H. J. Singer, and C. T. Russell (2002), Modeling the ring current magnetic field during storms, J. Geophys. Res., 107(A7), doi:10.1029/2001JA900101.

Ganushkina, N. Y., T. I. Pulkkinen, M. V. Kubyshkina, H. J. Singer, C. T. Russell (2004), Long-term evolution of magnetospheric current systems during storms, Ann. Geophys., $22,1317-1334$.

Ganushkina, N. Y., M. Liemohn, M. Kubyshkina, R. Ilie, H. Singer (2010), Distortions of the Magnetic Field by Storm-Time Current Systems in Earth's Magnetosphere, Ann. Geophys., 28, 123-140.

Ganushkina, N. Y., et al. (2015), Defining and resolving current systems in geospace, Ann. Geophys., 33, 1369-1402, doi:10.5194/angeo-33-1369-2015.

Gauss, C. F. (1839), Allgemeine Theorie des Erdmagnetismus. Resultate aus den Beobachtugen des magnetischen Vereins im Jahre 1838, Leipzig. (Reprinted in Werke, 5, 119193, Königliche Gesellschaff der Wissenschaften, Göttingen, 1877.)

Gillmor, C. S. (1997), The Formation and Early Evolution of Studies of the Magnetosphere, in Discovery of the Magnetosphere (eds C. S. Gillmor and J. R. Spreiter), American Geophysical Union, Washington, D. C.. doi:10.1029/HG007p0001.

Gkioulidou, M., A. Y. Ukhorskiy, D. G. Mitchell, and L. J. Lanzerotti (2016), Storm time dynamics of ring current protons: Implications for the long-term energy budget in the inner magnetosphere, Geophys. Res. Lett., 43, 4736-4744, doi:10.1002/2016GL068013.

Goldstein, J., R. W. Spiro, P. H. Reiff, R. A. Wolf, B. R. Sandel, J. W. Freeman, and R. L. Lambour (2002), IMF-driven overshielding electric field and the origin of the plasmaspheric shoulder of May 24, 2000, Geophys. Res. Lett., 29(16), doi:10.1029/2001GL014534.

Goldstein, J., R. W. Spiro, B. R. Sandel, R. A. Wolf, S.-Y. Su, and P. H. Reiff (2003), Overshielding event of 28-29 July 2000, Geophys. Res. Lett., 30, 1421, doi:10.1029/2002GL016644, 8.

Goldstein, J., P. Valek, D.J. McComas, J. Redfern (2012), TWINS energetic neutral atom observations of local-time-dependent ring current anisotropy, J. Geophys. Res., 117, 11213, doi:10.1029/2012JA017804.

Gonzales, C.A., M.C. Kelley, L.A. Carpenter, R.H. Holzworth (1978), Evidence for a magnetospheric effect on mid-latitude electric fields, J. Geophys. Res., 83, 4397-4399. 
Gordon, A. L. (1986), Interocean exchange of thermocline water, J. Geophys. Res., 91(C4), 5037-5046, doi:10.1029/JC091iC04p05037.

Grad, H. (1964), Some new variational properties of hydromagnetic equilibria, Phys. Fluids, 7, 1283 - 1292, doi:10.1063/1.1711373.

Iijima, T., and T. A. Potemra (1976a), The amplitude distribution of field-aligned currents at northern high latitudes observed by Triad, J. Geophys. Res., 81, 2165.

Iijima, T., and T. A. Potemra, Field-Aligned Currents in the Dayside Cusp Observed by Triad, J. Geophys. Res., 81, 5971-5979, doi:10.1029/JA081i034p05971, 1976b.

Iijima, T., and T. A. Potemra (1982), The relationship between interplanetary quantities and Birkeland current densities, Geophys. Res. Lett., 9, 442-445, doi: 10.1029/GL009i004p00442.

Iijima, T., R. Fujii, T. A. Potemra, and N. A. Saflekos, Field-aligned currents in the south polar cusp and their relationship to the interplanetary magnetic field, J. Geophys. Res., 83(A12), 5595-5603, doi:10.1029/JA083iA12p05595, 1978.

Iijima, T., T. A. Potemra, L. J. Zanetti, and P. F. Bythrow, Large-Scale Birkeland Currents in the Dayside Polar Region During Strongly Northward IMF: A New Birkeland Current System, J. Geophys. Res., 89(A9), 7441-7452, doi:10.1029/JA089iA09p07441, 1984.

Iijima, T., T. A. Potemra, and L. J. Zanetti (1990), Large-scale characteristics of magnetospheric equatorial currents, J. Geophys. Res., 95, 991.

Jacquey, C., J. A. Sauvaud, J. Dandouras, A. Korth (1993), Tailward propagating cross-tail current disruption and dynamics of near-Earth tail: Multi-point measurement analysis, Geophys. Res. Lett., 20, 983.

Jellinek, A. M., and M. Manga (2004), Links between long-lived hot spots, mantle plumes, D", and plate tectonics, Rev. Geophys., 42, RG3002, doi:10.1029/2003RG000144.

Jorgensen, A. M., H. E. Spence, W. J. Hughes, and H. J. Singer (2004), A statistical study of the global structure of the ring current, J. Geophys. Res., 109, A12204, doi:10.1029/2003JA010090.

Haaland, S. E., B. U. Sonnerup, M. W. Dunlop, et al. (2004), Four-spacecraft determination of magnetopause orientation, motion and thickness: comparison with results from single-spacecraft methods, Ann. Geophys., 22, 1347-1365. 
Hairston, M. R., T. W. Hill, and R. A. Heelis (2003), Observed saturation of the ionospheric polar cap potential during the 31 March 2001 storm, Geophys. Res. Lett., 30, 1325, doi:10.1029/2002GL015894, 6.

Hedgecock, P. C. and Thomas, B. T. (1975), HEOS Observations of the Configuration of the Magnetosphere, Geophysical Journal of the Royal Astronomical Society, 41, 391-403, doi:10.1111/j.1365-246X.1975.tb01622.x

Heikkila, W. J. (1984), Magnetospheric Topology of Fields and Currents, in Magnetospheric Currents (ed T. A. Potemra), American Geophysical Union, Washington, D. C., doi:10.1029/GM028p0208.

Heinemann, M. (1990), Representations of currents and magnetic fields in anisotropic magnetohydrostatic plasma, J. Geophys. Res., 95, 7789-7797.

Heinemann, M. and D. H. Pontius, Jr. (1991), Representation of currents and magnetic fields in anisotropic magnetohydrostatic plasma. 2. General theory and examples, $J$. Geophys. Res., 96, 17605-17626.

Hill, T. W., A. J. Dessler, and R. A. Wolf (1976), Mercury and Mars: The role of ionospheric conductivity in the acceleration of magnetospheric particles, Geophys. Res. Lett., 3, 429-432, doi:10.1029/GL003i008p00429.

Hilmer, R. V. and Voigt, G.-H. (1995), A magnetospheric magnetic field model with flexible current systems driven by independent physical parameters, J. Geophys. Res., 100, 5613-5626.

Hones Jr., E. W. (1979), Transient phenomena in the magnetotail and their relation to substorms, Space Sci. Rev., 23, 393.

Horton, W., R. S. Weigel, D. Vassiliadis, and I. Doxas (2003), Substorm classification with the WINDMI model, Nonlinear Processes Geophys., 10, 363.

Horton, W., M. Mithaiwala, E. Spencer, and I. Doxas (2005), WINDMI: A family of physics network models for storms and substorms, in Multi-Scale Coupling of SunEarth Processes, edited by A. Lui, Y. Kamide, and G. Consolini, Elsevier, New York. Huba, J. D., and S. Sazykin (2014), Storm time ionosphere and plasmasphere structuring: SAMI3-RCM simulation of the 31 March 2001 geomagnetic storm, Geophys. Res. Lett., 41(23), 8208.

Kamide, Y. (1974), Association of DP and DR fields with the interplanetary magnetic field variation, J. Geophys. Res., 79(1), 49-55, doi:10.1029/JA079i001p00049. 
Kamide, Y., and N. Fukushima (1971), Analysis of Magnetic Storms with

DR Indices for Equatorial Ring-Current Field, Radio Sci., 6(2), 277-278, doi:10.1029/RS006i002p00277.

Katus, R. M., M. W. Liemohn, E. Ionides, R. Ilie, D. T. Welling, and L. K. Sarno-Smith (2015), Statistical analysis of the geomagnetic response to different solar wind drivers and the dependence on storm intensity, J. Geophys. Res. Space Physics, 120, 310-327, doi: 10.1002/2014JA020712.

Keiling, A. (2009), Alfven waves and their roles in the dynamics of the Earth's magnetotail: A review, Space Sci. Rev., 142, 73. doi:10.1007/s11214-008-9463-8.

Kepko, L., Glassmeier, K.-H., Slavin, J. A. and Sundberg, T. (2015), Substorm Current Wedge at Earth and Mercury, in Magnetotails in the Solar System (eds A. Keiling, C. M. Jackman and P. A. Delamere), John Wiley \& Sons, Inc, Hoboken, NJ. doi:10.1002/9781118842324.ch21.

Kistler, L. M., et al. (2016), The source of O+ in the storm time ring current, J. Geophys. Res. Space Physics, 121, 5333-5349, doi:10.1002/2015JA022204.

Introduction to Space Physics, Edited by Margaret G. Kivelson and Christopher T. Russell, pp. 586, Cambridge, UK, Cambridge University Press, 1995.

Kivelson, M. G., and A. J. Ridley (2008), Saturation of the polar cap potential: Inference from Alfven wing arguments, J. Geophys. Res., 113, A05214, doi:10.1029/2007JA012302.

Komar, C. M., R. L. Fermo, and P. A. Cassak (2015), Comparative analysis of dayside magnetic reconnection models in global magnetosphere simulations, J. Geophys. Res. Space Physics, 120, 276-294, doi:10.1002/2014JA020587.

Korenaga, J. (2008), Urey ratio and the structure and evolution of Earth's mantle, Rev. Geophys., 46, RG2007, doi:10.1029/2007RG000241.

Korth, A., Friedel, R. H. W., Mouikis, C. G., Fennell, J. F., Wygant, J. R., and Korth, H. (2000), Comprehensive particle and field observations of magnetic storms at different local times from the CRRES spacecraft, J. Geophys. Res., 105, 18729-18740.

Kozyra, J. U. and M.W. Liemohn (2003), Ring current energy input and decay, Space Sci. Rev., 109, 105-131.

Kubyshkina, M. V., Pulkkinen, T. I., Ganushkina, N. Yu., Partamies, N. (2008), Magnetospheric currents during sawtooth events: Eventoriented magnetic field model analysis, $J$. Geophys. Res., 113, A08211, doi:10.1029/2007JA012983. 
Kuijpers, J., Frey, H. U., and Fletcher, L. (2015), Electric currents in astrophysics, Space Sci.Rev., 188, 3, doi:10.1007/s11214-014-0041-y.

Le, G. and Russell, C. T. (1994), The thickness and structure of high beta magnetopause current layer, Geophys. Res. Lett., 21, 2451-2454, doi:10.1029/94GL02292.

Le, G., C. T. Russell, and K. Takahashi (2004), Morphology of the ring current derived from magnetic field observations, Ann. Geophys., 22, 1267.

Le, G., H. Lühr, B. J. Anderson, R. J. Strangeway, C. T. Russell, H. Singer, J. A. Slavin, Y. Zhang, T. Huang, K. Bromund, et al. (2016), Magnetopause erosion during the 17 March 2015 magnetic storm: Combined field-aligned currents, auroral oval, and magnetopause observations, Geophys. Res. Lett., 43, 2396-2404, doi:10.1002/2016GL068257.

Liemohn, M. W., and P. C. Brandt (2005), Small-scale structure in the stormtime ring current, in Inner Magnetosphere Interactions: New Perspectives from Imaging, AGU Monogr. Ser., vol. 159, ed. by J. L. Burch, M. Schulz, and H. Spence, p. 167, Am. Geophys. Un., Washington, D. C.

Liemohn, M. W., J. U. Kozyra, C. R. Clauer, and A. J. Ridley (2001), Computational analysis of the near-Earth magnetospheric current system during two-phase decay storms, J. Geophys. Res., 106(A12), 29531-29542, doi:10.1029/2001JA000045.

Liemohn, M. W., A. J. Ridley, D. L. Gallagher, D. M. Ober, J. U. Kozyra (2004), Dependence of plasmaspheric morphology on the electric field description during the recovery phase of the April 17, 2002 magnetic storm, J. Geophys. Res., 109(A3), A03209, doi: 10.1029/2003JA010304.

Liemohn, M. W., A. J. Ridley, P. C. Brandt, D. L. Gallagher, J. U. Kozyra, D. G. Mitchell, E. C. Roelof, and R. DeMajistre (2005), Parametric analysis of nightside conductance effects on inner magnetospheric dynamics for the 17 April 2002 storm, J. Geophys. Res., 110, A12S22, doi: 10.1029/2005JA011109.

Liemohn, M. W., A. J. Ridley, J. U. Kozyra, D. L. Gallagher, M. F. Thomsen, M. G. Henderson, M. H. Denton, P. C. Brandt, and J. Goldstein (2006), Analyzing electric field morphology through data-model comparisons of the GEM IM/S Assessment Challenge events, J. Geophys. Res., 111, A11S11, doi: 10.1029/2006JA011700.

Liemohn, M. W., D. L. De Zeeuw, R. Ilie, and N. Yu. Ganushkina (2011), Deciphering magnetospheric cross-field currents, Geophys. Res. Lett., 38, L20106, doi: 10.1029/2011GL049611. 
Liemohn, M. W., Ganushkina, N. Y., Katus, R. M., De Zeeuw, D. L., and Welling,

D. T.: The magnetospheric banana current, J. Geophys. Res., 118, 1009-1021, doi:10.1002/jgra.50153, 2013a.

Liemohn, M. W., D. L. De Zeeuw, N. Y. Ganushkina, J. U. Kozyra, and D. T. Welling (2013b), Magnetospheric cross-field currents during the January 6-7, 2011, high-speed stream-driven interval, J. Atmos. Solar-Terr. Phys., 99, 78-84, doi: 10.1016/j.jastp.2012.09.007.

Liemohn, M. W., Katus, R. M., and Ilie, R. (2015), Statistical analysis of storm-time nearEarth current systems, Ann. Geophys., 33, 965-982, doi:10.5194/angeo-33-965-2015.

Liemohn, M. W., N. Y. Ganushkina, R. Ilie, D. T. Welling (2016), Challenges associated with near-Earth nightside current, J. Geophys. Res. Space Phys., 121(7), 6763.

Liu, J., V. Angelopoulos, A. Runov, and X.-Z. Zhou (2013), On the current sheets surrounding dipolarizing flux bundles in the magnetotail: The case for wedgelets, J. Geophys. Res. Space Physics, 118, 2000-2020, doi: 10.1002/jgra.50092.

Lockwood, M., S. W. H. Cowley, and M. P. Freeman (1990), The excitation of plasmac onvectionin the high-latitudeio nosphere, J. Geophys. Res., 95, 7961.

Lockwood, M. (2016), Jim Dungey, The Open Magnetosphere, and Space Weather, Space Weather, 14, 380-383, doi:10.1002/2016SW001438.

Lopez, R. E. (2016), The integrated dayside merging rate is controlled primarily by the solar wind, J. Geophys. Res. Space Physics, 121, 4435-4445, doi:10.1002/2016JA022556.

Lopez, R. E., and A. T. Y. Lui (1990), A multisatellite case study of the expansion of a substorm current wedge in the near-Earth magnetotail, J. Geophys. Res., 95(A6), 80098017, doi:10.1029/JA095iA06p08009.

Lopez, R. E., R. Bruntz, E. J. Mitchell, M. Wiltberger, J. G. Lyon, and V. G. Merkin (2010), Role of magnetosheath force balance in regulating the dayside reconnection potential, J. Geophys. Res., 115, A12216, doi:10.1029/2009JA014597.

Lotko, W., B. U. Sonnerup, and R. L. Lysak (1987), Nonsteady Boundary Layer Flow Including Ionospheric Drag and Parallel Electric Fields, J. Geophys. Res., 92(A8), 86358648, doi:10.1029/JA092iA08p08635.

Lotko, W. (2007), The magnetosphere-ionosphere system from the perspective of plasma circulation: A tutorial, J. Atmos. Solar-Terr. Phys., 69(3), 191. 
Lui, A. T. Y. (1991), A synthesis of magnetospheric substorm models, J. Geophys. Res., 96(A2), 1849-1856, doi:10.1029/90JA02430.

Lui, A. T. Y. (2000), Electric Current Approach to Magnetospheric Physics and the Distinction Between Current Disruption and Magnetic Reconnection, in Magnetospheric Current Systems (eds S.-I. Ohtani, R. Fujii, M. Hesse and R. L. Lysak), American Geophysical Union, Washington, D. C.. doi:Âă10.1029/GM118p0031.

Lui, A. T. Y. (2003), Inner magnetospheric plasma pressure distribution and its local time asymmetry, Geophys. Res. Lett., 30, 1846, doi:10.1029/2003GL017596.

Lui, A. T. Y., and D. C. Hamilton, Radial profiles of quiet time magnetospheric parameters, J. Geophys. Res., 97, 19,325-19,332, 1992.

Lui, A. T. Y., R. W. McEntire, and S. M. Krimigis, Evolution of the ring current during two geomagnetic storms, J. Geophys. Res., 92(A7), 7459-7470, 1987.

Lühr, H., C. Xiong, N. Olsen, G. Le (2017), Near-Earth Magnetic Field Effects of LargeScale Magnetospheric Currents, Space Sci. Rev., 206, 521-545, DOI 10.1007/s11214016-0267-y.

Maezawa, K., Magnetospheric Convection Induced by the Positive and Negative Z Components of the Interplanetary Magnetic Field: Quantitative Analysis Using Polar Cap Magnetic Records, J. Geophys. Res., 81(13), 2289-2303, doi:10.1029/JA081i013p02289, 1976.

Maltsev, Y.P. (2004), Points of Controversy in the Study of Magnetic Storms, Space Sci. Rev., 110, 227-277.

Mannucci, A. J., B. T. Tsurutani, M. A. Abdu, W. D. Gonzalez, A. Komjathy, E. Echer, B. A. Iijima, G. Crowley, and D. Anderson (2008), Superposed epoch analysis of the dayside ionospheric response to four intense geomagnetic storms, J. Geophys. Res., 113, A00A02, doi:10.1029/2007JA012732.

Mannucci, A. J., B. T. Tsurutani, M. C. Kelley, B. A. Iijima, and A. Komjathy (2009), Local time dependence of the prompt ionospheric response for the 7, 9, and 10 November 2004 superstorms, J. Geophys. Res., 114, A10308, doi:10.1029/2009JA014043.

Mauk, B. H., and L. J. Zanetti (1987), Magnetospheric electric fields and currents, Rev. Geophys., 25(3), 541-554.

Mauk, B. H., N. J. Fox, S. G. Kanekal, R. L. Kessel, D. G. Sibeck, and A. Ukhorskiy (2013), Science objectives and rationale for the Radiation Belt Storm Probes mission, Space Sci. Rev., 179, 3-27, doi: 10.1007/s11214-012-9908-y. 
McPherron, R. L. (2015), Earth's Magnetotail, in Magnetotails in the Solar System (eds A. Keiling, C. M. Jackman and P. A. Delamere), John Wiley \& Sons, Inc, Hoboken, NJ. doi:10.1002/9781118842324.ch4.

McPherron, R. L., C. T. Russell, M. G. Kivelson, and P. J. Coleman Jr. (1973a), Substorms in space: The correlation between ground and satellite observations of the magnetic field, Radio Sci., 8(11), 1059-1076, doi:10.1029/RS008i011p01059.

McPherron, R. L., C. T. Russell, and M. P. Aubry (1973b), Satellite studies of magnetospheric substorms on August 15, 1968: 9. Phenomenological Model for Substorms, J. Geophys. Res., 78(16), 3131-3149, doi:10.1029/JA078i016p03131.

Mead, G. D., and D. H. Fairfield (1975), A Quantitative Magnetospheric Model Derived From Spacecraft Magnetometer Data, J. Geophys. Res., 80, 523-534.

Meng, C.-I., and S.-I. Akasofu (1969), A study of polar magnetic substorms:

2. Three-dimensional current system, J. Geophys. Res., 74(16), 4035-4053, doi:10.1029/JA074i016p04035.

Merkin, V. G., K. Papadopoulos, G. Milikh, A. S. Sharma, X. Shao, J. Lyon, and C. Goodrich (2003), Effects of the solar wind electric field and ionospheric conductance on the cross polar cap potential: Results of global MHD modeling, Geophys. Res. Lett., 30, 2180, doi:10.1029/2003GL017903, 23.

Merkin, V. G., A. S. Sharma, K. Papadopoulos, G. Milikh, J. Lyon, and C. Goodrich (2005), Global MHD simulations of the strongly driven magnetosphere: Modeling of the transpolar potential saturation, J. Geophys. Res., 110, A09203, doi:10.1029/2004JA010993.

Merkin, V. G., B. J. Anderson, J. G. Lyon, H. Korth, M. Wiltberger, and T. Motoba (2013), Global evolution of Birkeland currents on 10 min timescales: MHD simulations and observations, J. Geophys. Res. Space Physics, 118, 4977-4997, doi:10.1002/jgra.50466.

Menz, A. M., L. M. Kistler, C. G. Mouikis, H. E. Spence, R. M. Skoug, H. O. Funsten, B. A. Larsen, D. G. Mitchell, M. Gkioulidou (2017), The role of convection in the buildup of the ring current pressure during the 17 March 2013 storm, J. Geophys. Res. Space Physics, 122, 475-492, doi:10.1002/2016JA023358.

Nagai, T. (1982), Observed magnetic substorm signatures at synchronous altitude, J. Geophys. Res., 87, 4405. 
Nakamura, R., W. Baumjohann, R. Schödel, M. Brittnacher, V. A. Sergeev, M. Kubyshkina, T. Mukai, and K. Liou (2001), Earthward flow bursts, auroral streamers, and small expansions, J. Geophys. Res., 106(A6), 10791-10802, doi:10.1029/2000JA000306.

Ness, N. F. (1965), The Earth's magnetic tail, J. Geophys. Res., 70(13), 2989-3005, doi:10.1029/JZ070i013p02989.

Ober, D. M., N. C. Maynard, W. J. Burke, G. R. Wilson, and K. D. Siebert (2006), "Shoulders" on the high-latitude magnetopause: Polar/GOES observations, J. Geophys. Res., 111, A10213, doi:10.1029/2006JA011799.

Ohtani, S., and T. Uozumi (2014), Nightside magnetospheric current circuit: Time constants of the solar wind-magnetosphere coupling, J. Geophys. Res. Space Physics, 119, 3558-3572, doi:10.1002/2013JA019680.

Ohtani, S., S. Kokubun, R. C. Elphic, and C. T. Russell (1988), Field-aligned current signatures in the near-tail region: 1. ISEE observations in the plasma sheet boundary layer, J. Geophys. Res., 93(A9), 9709-9720, doi:10.1029/JA093iA09p09709.

Ohtani, S., S. Kokubun, R. Nakamura, R. C. Elphic, C. T. Russell, and D. N. Baker (1990), Field-aligned current signatures in the near-tail region: 2. Coupling between the region 1 and the region 2 systems, J. Geophys. Res., 95(A11), 18913-18927, doi:10.1029/JA095iA11p18913.

Ohtani, S., T. A. Potemra, P. T. Newell, L. J. Zanetti, T. Iijima, M. Watanabe, M. Yamauchi, R. D. Elphinstone, O. de la Beaujardiere, and L. G. Blomberg (1995), Simultaneous Prenoon and Postnoon Observations of Three Field-Aligned Current Systems from Viking and DMSP-F7, J. Geophys. Res., 100(A1), 119-136, doi:10.1029/94JA02073.

Ohtani, S., K. Takahashi, T. Higuchi, A. T. Y. Lui, H. E. Spence, and J. F. Fennell (1998), AMPTE/CCE-SCATHA simultaneous observations of substorm-associated magnetic fluctuations, J. Geophys. Res., 103(A3), 4671-4682, doi:10.1029/97JA03239.

Opgenoorth H, . J., R. J. Pellinen, J . Maurer, F. Kiippers, W . J. Heikkila, K. U. Kaila, and P. Tanskanen (1980), Ground-based observations of an onset of localized fieldaligned currents during auroral breakup around magnetic midnight, J. Geophys. Res., $4,101$.

Owen, C. J., J. A. Slavin, I. G. Richardson, N. Murphy, and R. J. Hynds (1995), Average motion, structure and orientation of the distant magnetotail determined from remote sensing of the edge of the plasma sheet boundary layer with $\mathrm{E}>35 \mathrm{keV}$ ions, J. Geo- 
phys. Res., 100(A1), 185-204, doi:10.1029/94JA02417.

Papitashvili, V. O., F. J. Rich, M. A. Heinemann, and M. R. Hairston (1999), Parameterization of the defense meteorological satellite program ionospheric electrostatic potentials by the interplanetary magnetic field strength and direction, J. Geophys. Res., 104, 177.

Parker, E. N. (1957), Newtonian development of the dynamical properties of ionized gases of low density, Phys. Rev., 107, 924-933.

Parker, E. N. (1996), The alternative paradigm for magnetospheric physics, J. Geophys. Res., 101, 10,587-10,625.

Parker, E. N. (2000) Newton, Maxwell, and Magnetospheric Physics, in Magnetospheric Current Systems, Geophys. Monogr. Ser., vol 118, eds. S.-I. Ohtani, R. Fujii, M. Hesse and R. L. Lysak, American Geophysical Union, Washington, D. C., doi:10.1029/GM118p0001.

Patra, S., E. Spencer, W. Horton, and J. Sojka (2011), Study of Dst/ring current recovery times using the WINDMI model, J. Geophys. Res., 116, A02212, doi:10.1029/2010JA015824.

Payne, A. E., and G. Magnusdottir(2016), Persistent landfalling atmospheric rivers over the west coast of North America, J. Geophys. Res. Atmos., 121, 13,287-13,300, doi:10.1002/2016JD025549.

Peymirat, C., A. D. Richmond, and A. T. Kobea (2000), Electrodynamic coupling of high and low latitudes: Simulations of shielding/overshielding effects, J. Geophys. Res., 105(A10), 22991-23003, doi:10.1029/2000JA000057.

Pi, X., M. Mendillo, W. J. Hughes, M. J. Buonsanto, D. P. Sipler, J. Kelly, Q. Zhou, G. Lu, and T. J. Hughes (2000), Dynamical effects of geomagnetic storms and substorms in the middle-latitude ionosphere: An observational campaign, J. Geophys. Res., 105(A4), 7403-7417, doi:10.1029/1999JA900460.

Phan, T. D., M. P. Freeman, L. M. Kistler, et al. (2001), Evidence for an extended reconnection line at the dayside magnetopause, Earth, Planets and Space, 53(6), 619.

Phan, T. D., C. P. Escoubet, L. Rezeau, et al. (2005), Magnetopause Processes, Space Sci. Rev., 118(1-4), 367-424.

Petrinec, S. M., and C. T. Russell (1996), Near-Earth magnetotail shape and size as determined from the magnetopause flaring angle, J. Geophys. Res., 101, 137-152. 
Pollock, C., K. Asamara, M.M. Balkey, J.L. Burch, H.O. Funsten, M. Grande, M. Gruntman, M. Henderson, J.-M. Jahn, M. Lampton, M.W. Liemohn, D.J. McComas, T. Mukai, S. Ritzau, M.L. Schattenburg, E. Scime, J.R. Shoug, P. Valek, M. Wuest (2001), First medium energy neutral atom MENA images of Earth's magnetosphere during substorm and storm-time, Geophys. Res. Lett., 28, 1147.

Potemra, T. A. (1979), Current systems in the Earth's magnetosphere: A Review of U.S. Progress for the 1975-1978 IUGG Quadrennial Report, Rev. Geophys., 17(4), 640-656, doi:10.1029/RG017i004p00640.

A. Pulkkinen, L. Rastätter, M. Kuznetsova et al. (2013), Community-wide validation of geospace model ground magnetic field perturbation predictions to support model transition to operations, Space Weather, 11, 369-385, doi:10.1002/swe.20056.

Raeder, J., Y. L. Wang, T. J. Fuller-Rowell, and H. J. Singer (2001), Global simulation of space weather effects of the Bastille Day storm, Sol. Phys., 204, 325.

Rastätter, L., G. Tóth, M.M. Kuznetsova, A.A. Pulkkinen (2014), CalcDeltaB: An efficient postprocessing tool to calculate ground-level magnetic perturbations from global magnetosphere simulations, Space Weather, 12, 553-565, doi:10.1002/2014SW001083.

Ridley, A. J., and M. W. Liemohn (2002), A model-derived storm time asymmetric ring current driven electric field description, J. Geophys. Res., 107(A8), doi:10.1029/2001JA000051.

Ridley, A. J., G. Lu, C. R. Clauer, and V. O. Papitashvili (1998), A statistical study of the ionospheric convection response to changing interplanetary magnetic field conditions using the assimilative mapping of ionospheric electrodynamics technique, J. Geophys. Res., 103(A3), 4023-4039, doi:10.1029/97JA03328.

Roelof, E. C. (1987), Energetic neutral atom image of a storm-time ring current, Geophys. Res. Lett., 14, 652.

Roelof, E. C. (1989), Remote sensing of the ring current using energetic neutral atoms, Adv. Space. Res., 9, 195-203.

Roelof, E. C. and Skinner, A. J. (2000), Extraction of ion distributions from magnetospheric ENA and EUV images, Space Sci. Rev., 91, 437-459.

Roelof, E. C., C:son Brandt, P., and Mitchell, D. G. (2004), Derivation of currents and diamagnetic effects from global plasma pressure distributions obtained by IMAGE/HENA, Adv. Space Res., 33, 747-751. 
Rostoker, G., C. W. Anderson III, D. W. Oldenburg, P. A. Camfield, D. I. Gough, and H. Porath (1970), Development of a polar magnetic substorm current system, J. Geophys. Res., 75(31), 6318-6323, doi:10.1029/JA075i031p06318.

Rycroft, M. J., and R. G. Harrison (2012), Electromagnetic Atmosphere-Plasma Coupling: The Global Atmospheric Electric Circuit, Space Sci. Rev., 168, 363, doi:10.1007/s11214-011-9830-8.

Schmidt, A. (1917), Erdmagnetismus, in: Enzyklopeadie der Mathem. Wiss., VI, 265-396.

Sergeev, V. A., L. I. Vagina, R. D. Elphinstone, J. S. Murphree, D. J. Hearn, L. L. Cogger, and M. L. Johnson (1996), Comparison of UV optical signatures with the substorm current wedge as predicted by an inversion algorithm, J. Geophys. Res., 101(A2), 26152627, doi:10.1029/95JA00537.

Sergeev, V. A., N. A. Tsyganenko, M. V. Smirnov, A. V. Nikolaev, H. J. Singer, and W. Baumjohann (2011), Magnetic effects of the substorm current wedge in a spread-out wire model and their comparison with ground, geosynchronous, and tail lobe data, $J$. Geophys. Res., 116, A07218, doi:10.1029/2011JA016471.

Sibeck, D.G., and V. Angelopoulos (2008), THEMIS Science Objectives and Mission Phases, Space Sci. Rev., 141(35), doi:10.1007/s11214-008-9393-5.

Siscoe, G. L., W. Lotko, and B. U. Sonnerup (1991), A High-Latitude, Low-Latitude Boundary Layer Model of the Convection Current System, J. Geophys. Res., 96(A3), 3487-3495, doi:10.1029/90JA02362.

Siscoe, G. L., N. U. Crooker, P. B. Erickson, et al. (2000), Global Geometry of Magnetospheric Currents Inferred from MHD Simulations, in Magnetospheric Current Systems (eds S.-I. Ohtani, R. Fujii, M. Hesse and R. L. Lysak), American Geophysical Union, Washington, D. C.. doi:Âă10.1029/GM118p0041.

Siscoe, G. L., N. U. Crooker, and K. D. Siebert (2002), Transpolar potential saturation: Roles of region 1 current system and solar wind ram pressure, J. Geophys. Res., 107(A10), 1321, doi:10.1029/2001JA009176.

Siscoe, G., J. Raeder, and A. J. Ridley (2004), Transpolar potential saturation models compared, J. Geophys. Res., 109, A09203, doi:10.1029/2003JA010318.

Sitnov, M. I., N. A. Tsyganenko, A. Y. Ukhorskiy, B. J. Anderson, H. Korth, A. T. Y. Lui, and P. C. Brandt (2010), Empirical modeling of a CIR-driven magnetic storm, J. Geophys. Res., 115, A07231, doi:10.1029/2009JA015169. 
Shi, Y., E. Zesta, and L. R. Lyons (2008), Modeling magnetospheric current response to solar wind dynamic pressure enhancements during magnetic storms: 1. Methodology and results of the 25 September 1998 peak main phase case, J. Geophys. Res., 113, A10218, doi:10.1029/2008JA013111.

Smith, E. J. (2001), The heliospheric current sheet, J. Geophys. Res., 106(A8), 1581915831, doi:10.1029/2000JA000120.

Smith, P.H., and R.A. Hoffman (1974), Direct observations in the dusk hours of the characteristics of the storm time ring current particles during the beginning of magnetic storms. J. Geophys. Res., 79, 966-971.

Sojka, J.J., M. David, R.W. Schunk, J.C. Foster, H.B. Vo (2004), A modeling study of the F region response to SAPS, J. Atmos. Sol. Terr. Phys., 66, 415-423, doi:10.1016/j.jastp.2003.11.003.

Southwood, D. J., and R. A. Wolf (1978), An assessment of the role of precipitation in magnetospheric convection, J. Geophys. Res., 83, 5227.

Speiser, T. W., and N. F. Ness (1967), The neutral sheet in the geomagnetic tail: Its motion, equivalent currents, and field line connection through it, J. Geophys. Res., 72(1), 131-141, doi:10.1029/JZ072i001p00131.

Spence, H. E., M. G. Kivelson, and R. J. Walker (1989), Magnetospheric plasma pressure in the midnight meridian: Observations from 2.5 to $35 \mathrm{Re}$, J. Geophys. Res., 94, 52645272.

Spiro, R. W., R. A. Wolf, and B. G. Fejer (1988), Penetration of high-latitudeelectric- field effects to low latitudes during SUNDIAL 1984, Ann. Geophys., 6, 39.

Stern, D. P. (1976), Representation of magnetic fields in space, Rev. Geophys., 14(2), 199214, doi:10.1029/RG014i002p00199.

Stephens, G. K., M. I. Sitnov, J. Kissinger, N. A. Tsyganenko, R. L. McPherron, H. Korth, and B. J. Anderson (2013), Empirical reconstruction of storm time steady magnetospheric convection events, J. Geophys. Res. Space Physics, 118, 6434-6456, doi:10.1002/jgra.50592.

Stephens, G. K., M. I. Sitnov, A. Y. Ukhorskiy, E. C. Roelof, N. A. Tsyganenko, and G. Le (2016), Empirical modeling of the storm time innermost magnetosphere using Van Allen Probes and THEMIS data: Eastward and banana currents, J. Geophys. Res. Space Physics, 121, 157-170, doi:10.1002/2015JA021700. 
Stern, D. P. (1977), Large-scale electric fields in the Earth's magnetosphere, Rev. Geophys., 15(2), 156-194, doi:10.1029/RG015i002p00156.

Stern, D. P. (1983), The origins of Birkeland currents, Rev. Geophys., 21(1), 125-138, doi:10.1029/RG021i001p00125.

Stern, D. P. (1989), A brief history of magnetospheric physics before the spaceflight era, Rev. Geophys., 27, 103-114.

Stern, D. P. (1996), A brief history of magnetospheric physics during the space age, Rev. Geophys., 34(1), 1-31, doi:10.1029/95RG03508.

Stewart, B. (1882), Terrestrial Magnetism, in Encyclopaedia Britannica, 9th ed., (U.S. ed., $1883,16,159-184)$.

Stratton, J. M., R. J. Harvey, and G. A. Heyler (2013), Mission overview for the Radiation Belt Storm Probes Mission, Space Sci. Rev., 179, 29-57, doi: 10.1007/s11214-012-9933$\mathrm{x}$.

Störmer, C. (1907), Sur les trajectories des corpuscles electrises dans l'espace sous l'action du magnetisme terrestre avec application aux aurores boreales, Arch. Sci. Phys. Nat., 24.

Takada, T., et al. (2008), Local field-aligned currents in the magnetotail and ionosphere as observed by a Cluster, Double Star, and MIRACLE conjunction, J. Geophys. Res., 113, A07S20, doi:10.1029/2007JA012759.

Tanaka, T. (1995), Generation mechanisms for magnetosphere-ionosphere current systems deduced from a three-dimensional MHD simulation of the solar wind-magnetosphereionosphere coupling process, J. Geophys. Res., 100, 12,057-12,074.

Tsyganenko, N. A. (1987), Global quantitative models of the geomagnetic field in the cislunar magnetosphere for difference disturbance levels, Planet. Space Sci., 35, 1347.

Tsyganenko, N. A. (1989), A magnetospheric magnetic field model with a warped tail current sheet, Planet. Space Sci., 37, 5.

Tsyganenko, N. A. (1995), Modeling the Earth's magnetospheric magnetic field confined within a realistic magnetopause, J. Geophys. Res., 100, 5599-5612.

Tsyganenko, N. A. (2000), Modeling the inner magnetosphere: The asymmetric ring current and Region 2 Birkeland currents revisited, J. Geophys. Res., 105(A12), 2773927754, doi:10.1029/ 2000JA000138.

Tsyganenko, N. A. and Sitnov, M. I. (2005), Modeling the dynamics of the inner magnetosphere during strong geomagnetic storms, J. Geophys. Res., 110, A03208, 
doi:10.1029/2004JA010798.

Tsyganenko, N. A. and Sitnov, M. I. (2007), Magnetospheric configurations from a high-resolution data-based magnetic field model, J. Geophys. Res., 112, A06225, doi:10.1029/2007JA012260.

Tsyganenko, N. A., S. B. P. Karlsson, S. Kokubun, T. Yamamoto, A. J. Lazarus, K. W. Ogilvie, C. T. Russell, and J. A. Slavin (1998), Global configuration of the magnetotail current sheet as derived from Geotail, Wind, IMP 8 and ISEE 1/2 data, J. Geophys. Res., 103(A4), 6827 6841, doi:10.1029/97JA03621.

Tverskoy B. A. (1982), On magnetospheric field-aligned currents, Geomagn. Aeron., 22, 991-995.

Untiedt, J., R. Pellinen, F. Kuppers, H. J. Opgenoorth, W. D. Pelster, W. Baumjohann, H. Ranta, J. Kangas, P. Czechowsky, and W. J. Heikkila (1978), Observations of the initial development of an auroral and magnetic substorm at magnetic midnight, J. Geophys. Res., 45, 41-56, 1978.

Vallat, C., Dandouras, I., Dunlop, M., Balogh, A., Lucek, E., Parks, G. K., Wilber, M., Roelof, E. C., Chanteur, G., and RÃlme, H. (2005), First current density measurements in the ring current region using simultaneous multi-spacecraft CLUSTER-FGM data, Ann. Geophys., 23, 1849-1865, doi:10.5194/angeo-23-1849-2005.

Vasyliunas, V. M. (1970), Mathematical models of magnetospheric convection and its coupling to the ionosphere, in Particles and Fields in the Magnetosphere, edited by B. M. McCormac, pp. 60 - 71, D. Reidel, Hingham, Mass.

Vasyliunas, V. M. (2001), Electric field and plasma flow: what drives what?, Geophys. Res. Lett., 28, 2177-2180, doi: 10.1029/2001GL013014.

Vasyliunas, V. M. (2005), Relation between magnetic fields and electric currents in plasmas, Ann. Geophys., 23, 2589-2597.

Walsh, A. P., S. Haaland, C. Forsyth, A. M. Keesee, J. Kissinger, K. Li, A. Runov, J. Soucek, B. M. Walsh, S. Wing, and M. G. G. T. Taylor (2014), Dawn-dusk asymmetries in the coupled solar wind-magnetosphere-ionosphere system: a review, Ann. Geophys., 32, 705-737, doi: 10.5194/angeo-32-705-2104.

Wei, Y., Z. Pu, M. Hong, Q. Zong, J. Liu, J. Guo, A. Ridley, W. Wan (2010), Long-lasting goodshielding at the equatorial ionosphere, J. Geophys. Res. Space Physics, 115, A12.

Weimer, D. R. (1996), A flexible, IMF dependent model of high-latitude electric potential having "space weather" applications, Geophys. Res. Lett., 23, 2549. 
Williams, D. J. (1987), Ring current and radiation belts, Rev. Geophys., 25, 570âĂŞ578.

Wing, S., and P. T. Newell (2000), Quiet time plasma sheet ion pressure contribution to Birkeland currents, J. Geophys. Res., 105(A4), 7793-7802, doi:10.1029/1999JA900464.

Winterhalter, D., E. J. Smith, M. E. Burton, N. Murphy, D. J. McComas (1994), The heliospheric plasma sheet, J. Geophys. Res., 99, 6667.

Wolf, R. A. (1970), Effects of ionospheric conductivity on convective flow of plasma in the magnetosphere. J. Geophys. Res., 75(25), 4677-4698.

Wolf, R. A., J. W. Freeman, Jr., B. A. Hausman, R. W. Spiro, R. V. Hilmer, and R. L. Lambour (1997), Modeling convection effects in magnetic storms, in Magnetic Storms, Geophys. Monogr. Ser., 98, edited by B. T. Tsurutani, W. D. Gonzalez, Y. Kamide, and J. K. Arballo, American Geophysical Union, p. 161.

Wolf, R. A., R. W. Spiro, S. Sazykin, F. R. Toffoletto (2007), How the Earth's inner magnetosphere works: An evolving picture, J. Atmos. Sol. Terr. Phys., 69, 288-302, doi:10.1016/j.jastp.2006.07.026.

Xing, X., L. R. Lyons, V. Angelopoulos, D. Larson, J. McFadden, C. Carlson, A. Runov, and U. Auster (2009), Azimuthal plasma pressure gradient in quiet time plasma sheet, Geophys. Res. Lett., 36, L14105, doi:10.1029/2009GL038881.

Xu, D., and M. G. Kivelson (1994), Polar cap field-aligned currents for southward interplanetary magnetic fields, J. Geophys. Res., 99(A4), 6067-6078, doi:10.1029/93JA02697.

Yang, J., F. R. Toffoletto, R. A. Wolf, S. Sazykin, P. A. Ontiveros, and J. M. Weygand (2012), Large-scale current systems and ground magnetic disturbance during deep substorm injections, J. Geophys. Res., 117, A04223, doi:10.1029/2011JA017415.

Yang, J., F. R. Toffoletto, R. A. Wolf, and S. Sazykin (2015), On the contribution of plasma sheet bubbles to the storm time ring current, J. Geophys. Res. Space Physics, 120, 7416âĂŞ7432, doi:10.1002/2015JA021398.

Zhao, H., X. Li, D. N. Baker et al. (2015), The evolution of ring current ion energy density and energy content during geomagnetic storms based on Van Allen Probes measurements, J. Geophys. Res. Space Physics, 120, 7493-7511, doi:10.1002/2015JA021533.

Zhao, H., X. Li, D. N. Baker, et al. (2016), Ring current electron dynamics during geomagnetic storms based on the Van Allen Probes measurements. J. Geophys. Res. Space Physics, 121, 3333-3346, doi:10.1002/2016JA022358.

Zheng, Y., A. T. Y. Lui, M.-C. Fok, B. J. Anderson, P. C. Brandt, T. J. Immel, and D. G. Mitchell (2006), Relationship between Region 2 field-aligned current and the ring cur- 
rent: Model results, J. Geophys. Res., 111, A11S06, doi: 10.1029/2006JA011603.

Zmuda, A. J., J. H. Martin, and F. T. Heuring (1966), Transverse Magnetic Disturbances at 1100 Kilometers in the Auroral Region, J. Geophys. Res., 71(21), 5033-5045, doi:10.1029/JZ071i021p05033.

Zmuda, A. J., and J. C. Armstrong (1974), The Diurnal Variation of the Region with Vector Magnetic Field Changes Associated with Field-Aligned Currents, J. Geophys. Res., 79(16), 2501-2502, doi:10.1029/JA079i016p02501. 


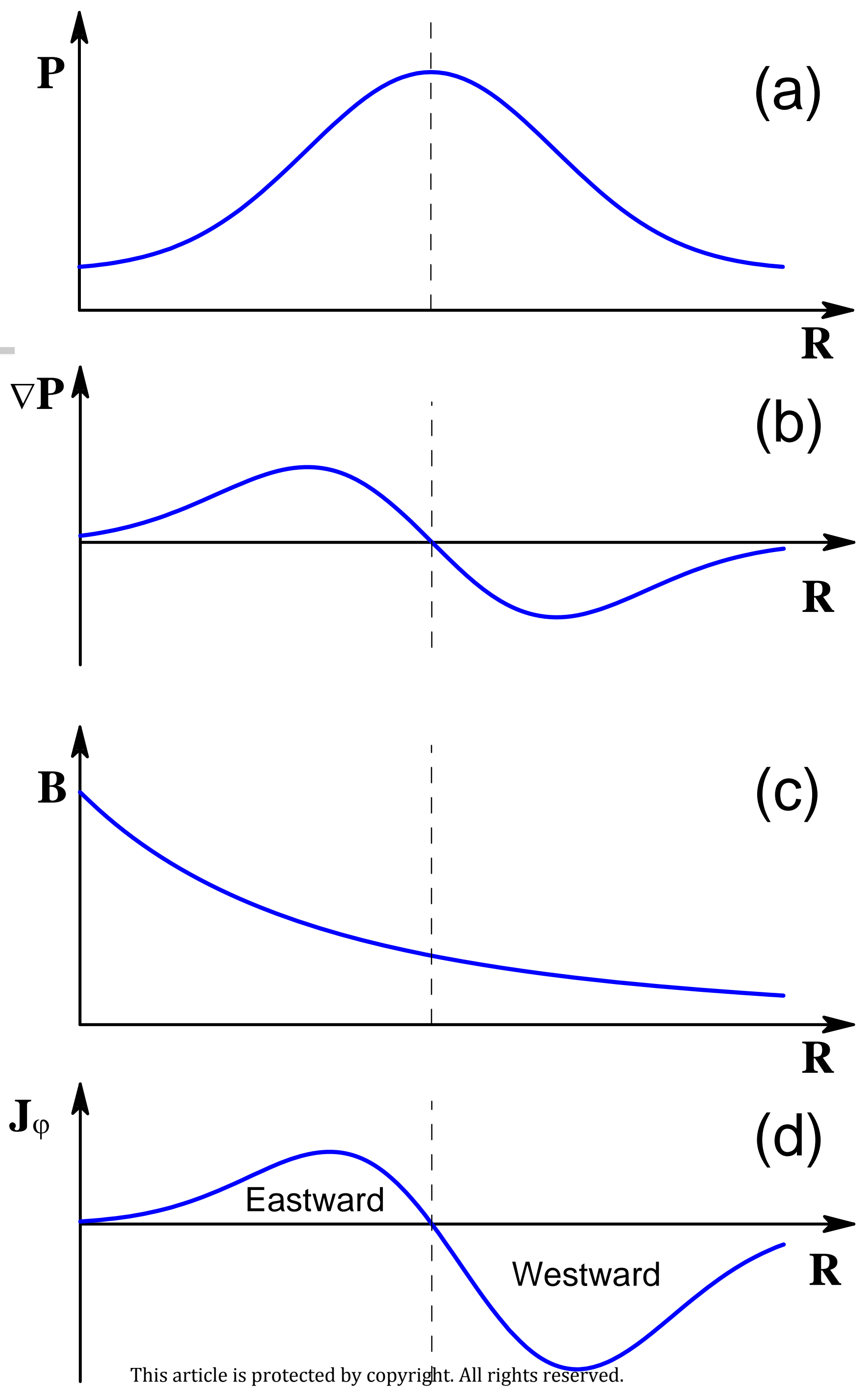


Figure 2.
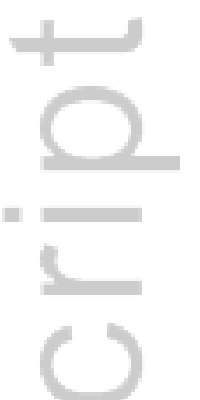

$\infty$
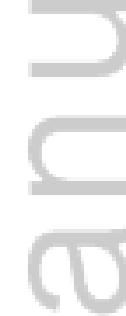

This article is protected by copyright. All rights reserved. 


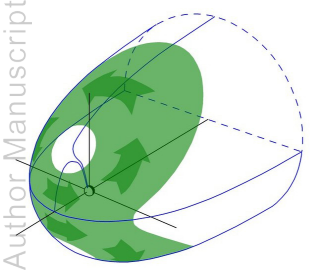




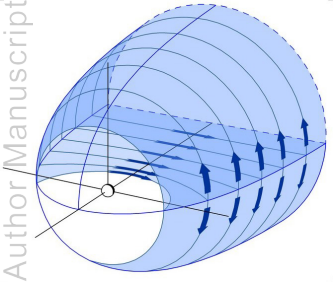




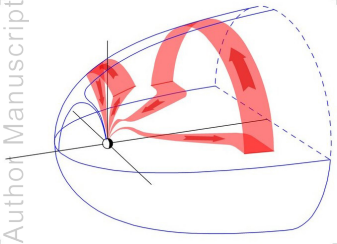


Figure 5.
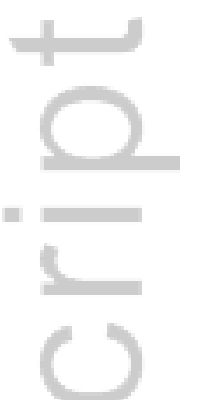

$\infty$
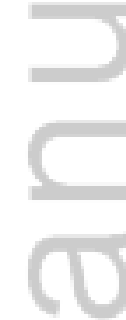

This article is protected by copyright. All rights reserved. 


$$
\text { c) }
$$




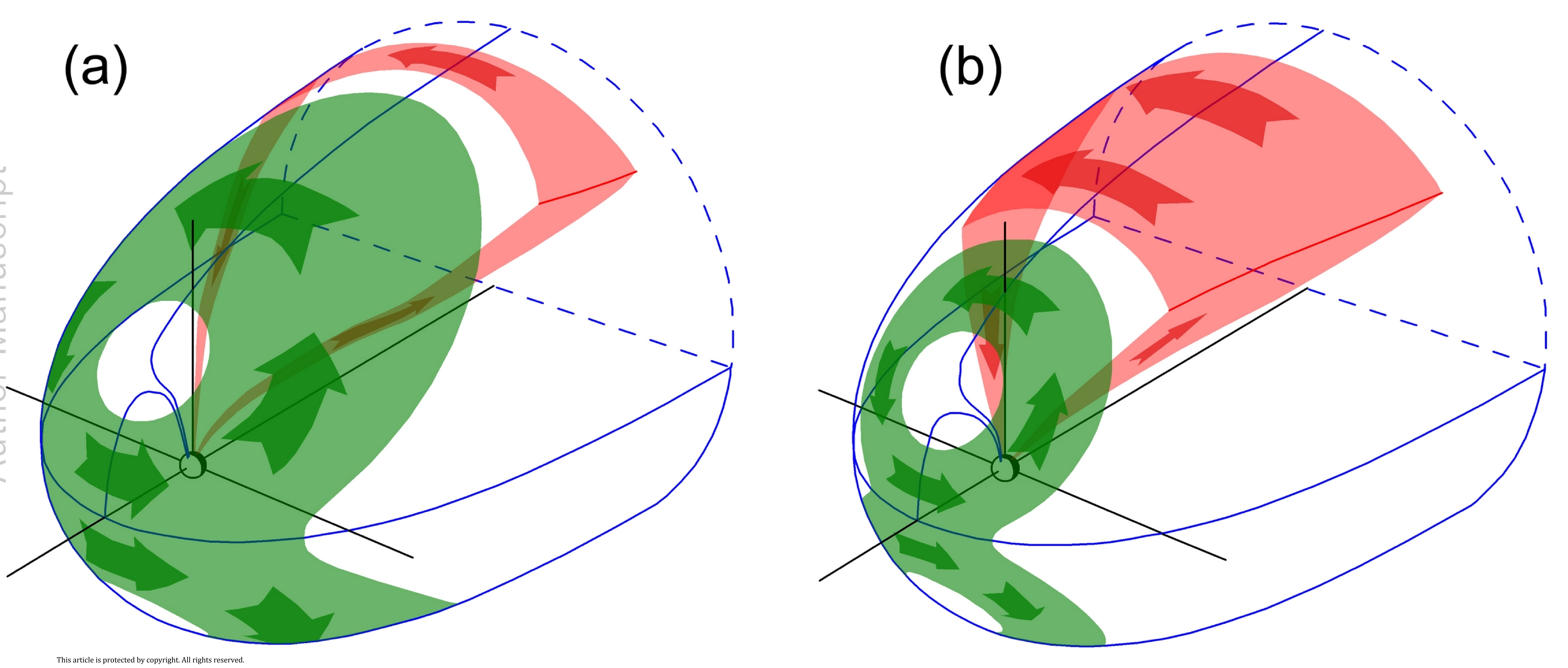




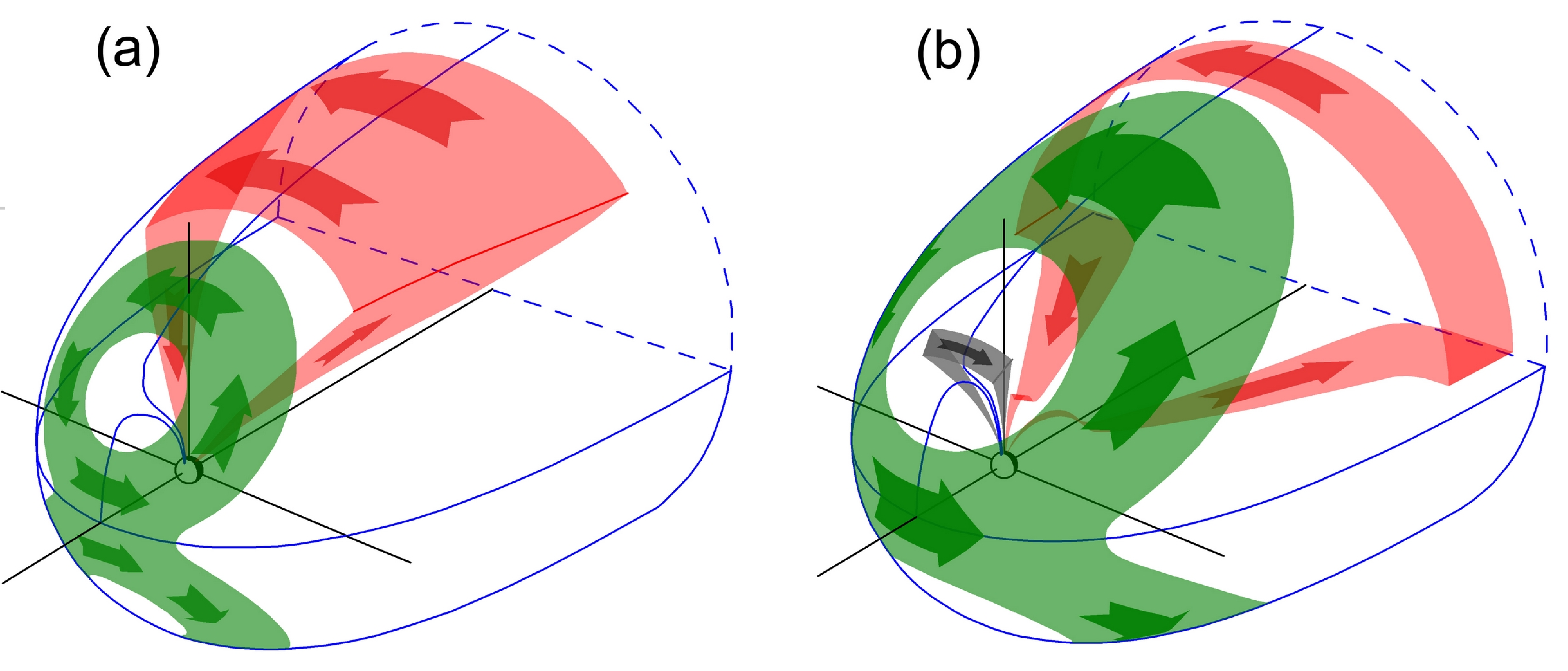


Figure 9.
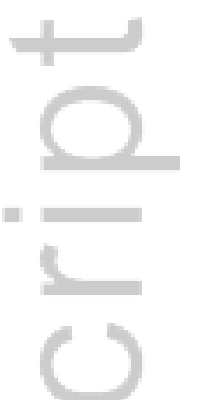

$\infty$
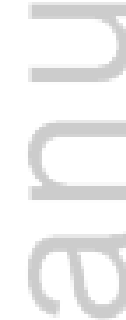

This article is protected by copyright. All rights reserved. 
(a)

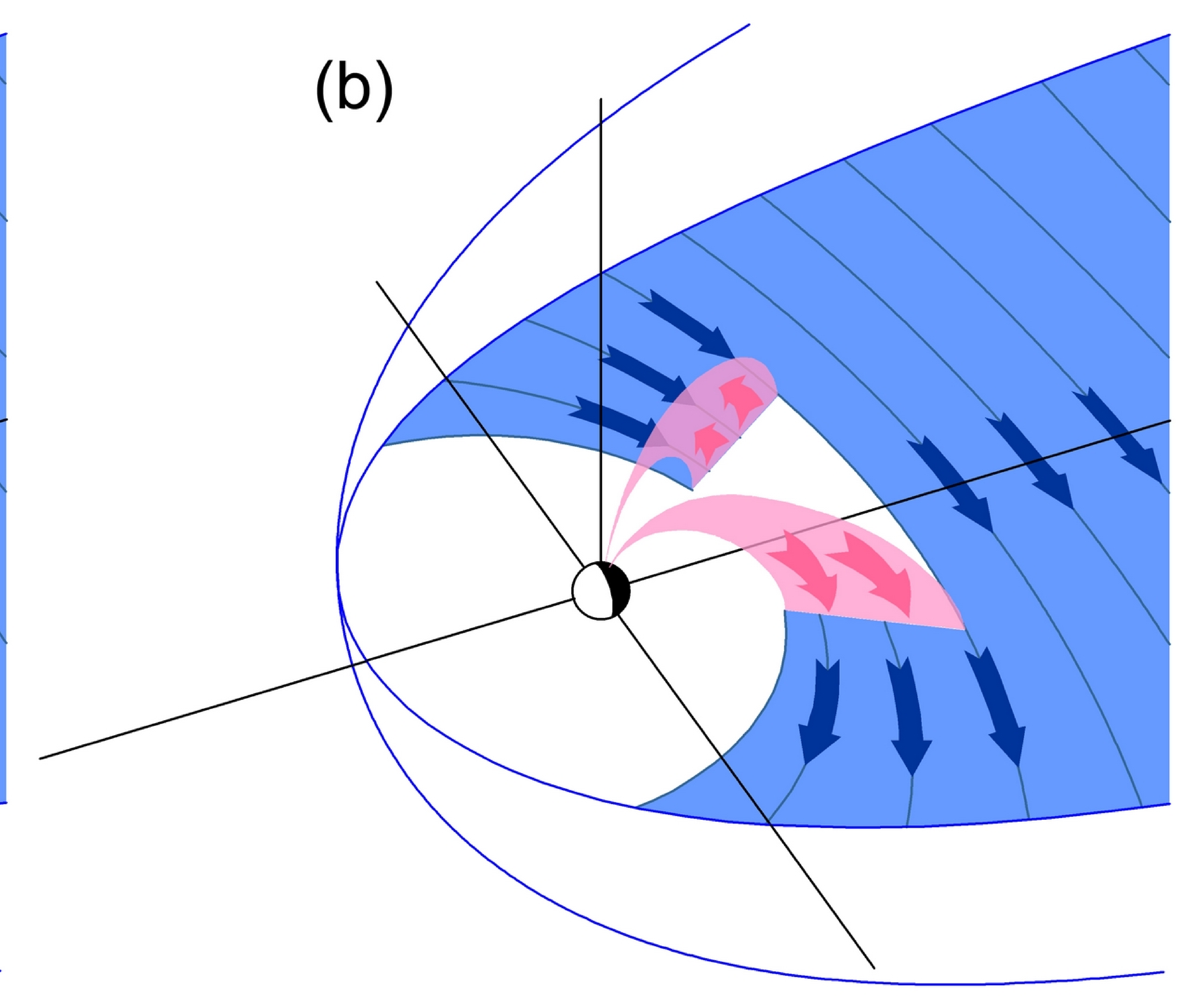




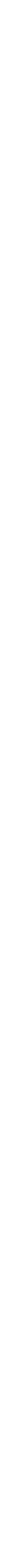

